OPEN ACCESS

Edited by:

Claudine Blin-Wakkach UMR7370 Laboratoire de Physio Médecine Moléculaire (LP2M), France

Reviewed by:

Irma Machuca-gayet,

Centre National de la Recherche

Scientifique (CNRS), France

Ari Elson,

Weizmann Institute of Science, Israel

Pieter J. M. Leenen,

Erasmus University Rotterdam,

Netherlands

*Correspondence: Attila Mócsai

mocsai.attila@

med.semmelweis-univ.hu

Specialty section:

This article was submitted to Inflammation,

a section of the journal

Frontiers in Immunology

Received: 16 December 2018

Accepted: 11 April 2019

Published: 30 April 2019

Citation:

Csete D, Simon E, Alatshan A, Aradi P.

Dobó-Nagy C, Jakus Z, Benkő $S$,

Győri DS and Mócsai A (2019)

Hematopoietic or Osteoclast-Specific

Deletion of Syk Leads to Increased

Bone Mass in Experimental Mice.

Front. Immunol. 10:937.

doi: 10.3389/fimmu.2019.00937

\section{Hematopoietic or}

\section{Osteoclast-Specific Deletion of Syk Leads to Increased Bone Mass in Experimental Mice}

\author{
Dániel Csete ${ }^{1}$, Edina Simon ${ }^{1}$, Ahmad Alatshan ${ }^{2}$, Petra Aradi 1,3, Csaba Dobó-Nagy ${ }^{4}$, \\ Zoltán Jakus ${ }^{1,3}$, Szilvia Benkö ${ }^{2}$, Dávid S. Györi ${ }^{1}$ and Attila Mócsai ${ }^{1 *}$ \\ ${ }^{1}$ Department of Physiology, Semme/weis University School of Medicine, Budapest, Hungary, ${ }^{2}$ Department of Physiology, \\ Faculty of Medicine, University of Debrecen, Debrecen, Hungary, ${ }^{3}$ MTA-SE "Lendület" Lymphatic Physiology Research \\ Group of the Hungarian Academy of Sciences and the Semmelweis University, Budapest, Hungary, ${ }^{4}$ Department of Oral \\ Diagnostics, Semmelweis University School of Dentistry, Budapest, Hungary
}

Syk is a non-receptor tyrosine kinase critically involved in signaling by various immunoreceptors including B-cell-receptors and activating Fc-receptors. We have previously shown that Syk also mediates immunoreceptor-like signals required for the in vitro development and function of osteoclasts. However, the perinatal lethality of Syk ${ }^{-1-}$ mice precluded the analysis of the role of Syk in in vivo bone metabolism. To overcome that problem, we generated mice with osteoclast-specific $\left(S y k^{\Delta \mathrm{OC}}\right)$ or hematopoietic (Syk ${ }^{\Delta \mathrm{Haemo})}$ Syk deficiency by conditional deletion of Syk using Cre recombinase expressed under the control of the Ctsk or Vav1 promoter, respectively. Micro-CT analysis revealed increased bone trabecular density in both $S y k^{\Delta \mathrm{OC}}$ and Syk ${ }^{\Delta \text { Haemo }}$ mice, although hematopoietic Syk deficiency caused a more severe phenotype than osteoclast-specific Syk deficiency. Osteoclast-specific Syk deficiency reduced, whereas hematopoietic Syk deficiency completely blocked in vitro development of osteoclasts. Both interventions inhibited the resorptive activity of osteoclasts and osteoclast-specific gene expression. Kinetic analysis of Syk protein levels, Cre expression and the genomic deletion of the Syk flox allele revealed complete and early deletion of Syk from Syk ${ }^{\Delta \text { Haemo }}$ osteoclasts whereas Syk was incompletely deleted at a later stage of osteoclast development from $S y k^{\Delta \mathrm{OC}}$ cultures. Those results provide an explanation for the in vivo and in vitro difference between the Syk ${ }^{\Delta O C}$ and Syk ${ }^{\Delta H a e m o}$ mutant strains and suggest late activation of, and incomplete target gene deletion upon, osteoclast-specific Cre expression driven by the Ctsk promoter. Taken together, our results indicate that Syk plays an indispensable role in osteoclast-mediated in vivo bone resorption and suggest that Syk-specific inhibitors may provide therapeutic benefit in inflammatory and other diseases characterized by excessive osteoclast-mediated bone resorption.

Keywords: SYK (spleen tyrosine kinase), tyrosine kinase, osteoclasts, Cre-Lox, in vivo, mice 


\section{INTRODUCTION}

Osteoclasts are multinuclear giant cells of hematopoietic origin which develop from myeloid progenitors through a unique biochemical maturation program followed by homotypic fusion $(1,2)$. Osteoclasts are the sole cell types in the mammalian organism capable of actively resorbing bone tissue and therefore play a critical role in bone homeostasis. Defective osteoclast development or function leads to increased bone mass (osteopetrosis) (3), whereas excessive (pathological) bone resorption occurs during osteoporosis (4), inflammatory joint diseases (e.g., arthritis-induced bone erosions in rheumatoid arthritis) $(5,6)$ and cancer-induced bone loss $(7,8)$.

Osteoclast development and function requires a number of extracellular cues including M-CSF, RANKL, as well as integrinmediated adhesive processes (9). The importance of those pathways is indicated by the severe bone resorption defects in mice lacking M-CSF (10), RANK $(11,12)$, RANKL $(13,14)$, or $\beta_{3}$ integrins (15). Culturing myeloid progenitors derived from human blood or mouse bone marrow in the presence of $\mathrm{M}$ CSF and RANKL also leads to formation of osteoclast-like cells with in vitro bone resorbing capacity, allowing the analysis of osteoclast development and function in cell culture.

Syk is a non-receptor tyrosine kinase critically involved in various functions of the immune system, as well as certain nonimmune-related biological processes (16). Syk is required for Bcell-receptor signaling and therefore the development of B-cells $(17,18)$. It is a critical component of signaling by a number of activating Fc-receptors such as Fce-receptors and Fc $\gamma$-receptors on neutrophils, macrophages, and mast cells (19-22), as well as the Fc-receptor-related collagen receptor GpVI of platelets $(23,24)$. Syk also mediates signaling by $\beta_{1}, \beta_{2}$, and $\beta_{3}$ integrins in neutrophils, monocytes/macrophages, and platelets (25-27). Syk deficiency causes perinatal lethality $(17,18)$ likely due to the role of Syk in lymphatic vascular development (28). Most, if not all of those functions of Syk is related to its binding to receptorassociated tyrosine-phosphorylated immunoreceptor tyrosinebased activation motifs (ITAMs) linking immunoreceptors to downstream signaling pathways $(16,29-32)$. The role of Syk in various immune and inflammatory processes also translates into its role in autoantibody-induced arthritis $(24,33-35)$ and dermatitis $(36,37)$ in experimental mice.

We and others have previously shown that the ITAMcontaining adapter molecules DAP12 and FcR $\gamma$ are involved in in vitro osteoclast development and function, and that mice lacking both DAP12 and FcR $\gamma$ show strongly increased mineralized bone mass (38-43). One of the possible mechanisms for those phenotypes could be that, similar to immune cells $(16,29)$, the ITAM-containing DAP12 and FcR $\gamma$ adapters would activate the Syk tyrosine kinase in osteoclasts, thus triggering osteoclast development and function. Indeed, Syk-deficient bone marrow cells failed to develop to mature multinucleated osteoclasts or to show resorptive activity in in vitro cultures $(40,42,44,45)$, and this in vitro phenotype was linked to ITAM signaling by DAP12 and FcR $\gamma(42-44)$. Those studies provided an unexpected link between immunoreceptor-like signaling and bone homeostasis and therefore provided one of the foundations of the field of osteoimmunology $(46,47)$. In addition, Sykmediated pathways have also been linked to integrin signal transduction and the osteoclast cytoskeleton $(16,26,42,44,48)$. Unfortunately, however, it is at present unclear whether Syk is also involved in bone homeostasis in live animals, as bone morphology of Syk-deficient animals could not be tested because of the perinatal lethality of $S y k^{-/-}$mice $(17,18)$.

To overcome the perinatal lethality of $S y k^{-/-}$animals, we have generated mice with osteoclast-specific or hematopoieticspecific Syk deletion using the Cre-Lox recombination approach. Analysis of the mice with tissue specific Syk deletion revealed strong increase in bone mass upon osteoclast-specific and, particularly, hematopoietic-specific Syk-deficiency, indicating a critical role for Syk in in vivo bone homeostasis. Further experiments aimed at understanding the different severities of the bone phenotypes in the two strains indicated that the effect of Syk deficiency on osteoclast development strongly depends on the timing and extent of Cre expression and Cre-mediated inactivation of the Syk gene.

\section{MATERIALS AND METHODS}

\section{Animals}

Mice carrying the $S y k^{\mathrm{tm} 1.2 \mathrm{Tara}}$ (referred to as $S y k^{\text {flox }}$ ) floxed allele of the Syk gene (49) were obtained from Alexander Tarakhovsky (Rockefeller University) and were maintained in homozygous $\left(S y k^{\text {flox/flox }}\right)$ form. Mice carrying the Ctsk ${ }^{\operatorname{tm} 1 \text { (cre)Ska }}$ (referred to as $\left.C t s k^{\mathrm{Cre}}\right)$ knock-in mutation resulting in the osteoclast-specific expression of the Cre recombinase under the control of the endogenous promoter of the Ctsk gene and at the same time inactivating the Ctsk gene (50) were obtained from Shigeaki Kato (University of Tokyo) and were maintained in heterozygous form (referred to as Ctsk-Cre) to avoid homozygous inactivation of the Ctsk gene. Mice carrying the Commd10 $\mathrm{Tg}$ (Vav1-icre)A2Kio transgenic insertional mutation expressing the Cre recombinase in the entire haemopoietic lineage from the exogenous Vav1 promoter (51) and at the same time inactivating the Commd10 gene (52) were obtained from the Jackson Laboratory and were maintained in heterozygous form (referred to as Vav-Cre) to avoid homozygous inactivation of the Commd10 gene. Mice carrying the $L y z 2^{\mathrm{tm} 1 \text { (cre)Ifo }}$ (referred to as $L y z 2^{\mathrm{Cre}}$ ) knock-in mutation expressing the Cre recombinase in the entire myeloid compartment from the endogenous promoter of lysozyme $\mathrm{M}$ (53) were purchased from the Jackson Laboratory and were maintained in homozygous form (referred to as LysM-Cre).

Osteoclast-specific deletion of $S y k$ was achieved by crossing the Ctsk-Cre and $S y k^{\text {flox/flox }}$ mice to obtain $C t s k^{\text {Cre } /+} S y k^{\text {flox/flox }}$ (referred to as $S y k^{\Delta \mathrm{OC}}$ ) animals. Deletion of Syk in the entire hematopoietic compartment was achieved by crossing the Vav-Cre and $S y k^{\text {flox/flox }}$ mice to obtain Commd10 10 (Vav1-icre)A2Kio/+ Sy $k^{\text {flox } / \text { flox }}$ (referred to as $S y k^{\Delta \text { Haemo }}$ ) animals. Myeloid-specific deletion of Syk was achieved by crossing the LysM-Cre and $S y k^{\text {flox/flox }}$ mice to obtain $L y z 2^{\mathrm{Cre} / \mathrm{Cre}} S y k^{\text {flox/flox }}$ (referred to as $S y k^{\Delta \text { Myelo }}$ ) animals. The allele obtained by Cre-mediated deletion of the $S y k^{\text {flox }}$ allele will be referred to as the $S y k^{\Delta}$ allele. 
Genotyping of the mice was performed by allele-specific PCR. All mice were on the C57BL/6 genetic background. Wild type C57BL/6 animals were obtained from our breeding colony. The mice were kept in individually sterile ventilated cages (Tecniplast) in a specific pathogen-free facility. All animal experiments were approved by the Animal Experimentation Review Board of Semmelweis University.

\section{Micro-CT Analysis}

Mice were sacrificed at 9 weeks of age and their right femurs were subjected to micro-CT analysis by a SkyScan 1172 microCT apparatus as described $(54,55)$. A $70 \mathrm{kV}$ and $124 \mu \mathrm{A}$ $\mathrm{X}$-ray source with $0.5 \mathrm{~mm}$ aluminum filter and a rotation step of $0.5^{\circ}$ was used during image acquisition, followed by reconstruction with the SkyScan NRecon software, resulting in an isometric $5 \mu \mathrm{m}$ voxel size. Volume of interest was selected according to the manufacturer's instructions. Further analysis was performed using the Skyscan CTAn and CTVol software. The lower threshold of binary images was set to an absolute value of 85 throughout the entire study. Our study design did not allow the calculation of absolute bone hydroxyapatite densities.

Quantitative analysis was performed on the trabecular region of the distal femoral metaphysis beginning 50 sections $(0.25 \mathrm{~mm})$ from the distal growth plate to an additional 400 sections $(2 \mathrm{~mm})$ to the proximal direction, including the entire trabecular area within that range, identified manually by visual inspection. Quantitative parameters included percent bone volume $(\mathrm{BV} / \mathrm{TV})$, trabecular number, trabecular thickness and trabecular separation as described $(54,55)$.

Representative cross sections represent the 200th section ( $1 \mathrm{~mm}$ ) from the distal femoral growth plate. 3D images show an axial cylinder of a diameter of $500 \mu \mathrm{m}$ between sections $150-450$ from the distal growth plate.

\section{Histological Procedures and Immunostaining}

Femurs isolated from mice at 9 weeks of age were fixed in $4 \%$ paraformaldehyde (Sigma-Aldrich) followed by decalcification in Osteomoll (Merck) for 3 weeks. The samples were then dehydrated, and embedded in paraffin (Leica) using a Leica EG1150H embedding station. Eight micrometers of thick sections were obtained using a Thermo Scientific HM340E microtome and were processed for hematoxylin and eosin (Leica) staining, or for immunostaining for the calcitonin receptor using anti-Calcitonin Receptor (Abcam AB11042) and antirabbit Alexa Fluor 488 (Life Technologies, A11034) antibodies. Microscopic images were taken by a Nikon ECLIPSE Ni-U microscope connected to a Nikon DS-Ri2 camera.

\section{In vitro Culture and Resorption Assays}

In vitro osteoclast cultures were performed essentially as described before $(54,55)$. Bone marrow cells obtained by flushing the tibia and femur of wild type or mutant mice were cultured in the presence of $10 \mathrm{ng} / \mathrm{ml}$ murine M-CSF (Peprotech) for 2 days in $\alpha$-MEM medium (Sigma) supplemented with $10 \%$ FCS (Gibco) and antibiotics. Non-adherent cells were then plated at the concentration of $1.5 \times 10^{5}$ cells $/ \mathrm{cm}^{2}$ and cultured in the presence of $50 \mathrm{ng} / \mathrm{ml}$ recombinant murine $\mathrm{M}-\mathrm{CSF}$ and $50 \mathrm{ng} / \mathrm{ml}$ murine RANKL (Peprotech) with medium changes every 2 days. In parallel macrophage cultures, the cells were cultured under identical conditions except that RANKL was omitted.

Cultures were terminated and osteoclast-specific staining was performed using a commercial tartrate-resistant acid phosphatase (TRAP) staining kit (Sigma-Aldrich) at the indicated times after the first addition of RANKL. Photomicrographs were taken using a Leica DMI6000B inverted microscope. The images were then analyzed either manually or by the ImageJ software. Osteoclasts were defined as TRAP-positive cells with 3 or more nuclei.

For in vitro resorption assays, osteoclasts were cultured under similar conditions for 7 days on an artificial hydroxyapatite surface (Sigma-Aldrich) followed by washing, imaging by dark field microscopy and further analysis by ImageJ software.

\section{Biochemical Studies}

For protein content analysis, osteoclast, or macrophage cultures were washed and then lysed in a Triton-based lysis buffer containing $100 \mathrm{mM} \mathrm{NaCl}, 30 \mathrm{mM}$ Na-HEPES (pH 7.4), $20 \mathrm{mM}$ NaF, $1 \mathrm{mM}$ Na-EGTA, $1 \%$ Triton $\mathrm{X}-100,1 \mathrm{mM}$ benzamidine, freshly supplemented with $0.1 \mathrm{U} / \mathrm{ml}$ Aprotinin, 1:100 Mammalian Protease Inhibitor Cocktail, 1:100 Phosphatase Inhibitor Cocktail 2, $1 \mathrm{mM}$ PMSF, and $1 \mathrm{mM} \mathrm{Na}_{3} \mathrm{VO}_{4}$ (all from Sigma-Aldrich). Insoluble material was removed, the lysate supernatants were supplemented with $4 \times$ Laemmli's sample buffer and boiled for $10 \mathrm{~min}$. Whole cell lysates were run on SDS-PAGE, electroblotted to nitrocellulose membranes, and then processed for immunoblotting with antibodies against Syk (N19; Santa Cruz) or $\beta$-actin (Clone AC-74; Sigma-Aldrich). After incubation with peroxidase-labeled secondary antibodies (GE Healthcare), the signal was developed using the ECL system (GE Healthcare) and exposed to X-ray film. X-ray films were then scanned and processed with Adobe Photoshop.

\section{Quantitative RT-PCR Analysis}

To test osteoclast specific and Cre gene expression changes, mouse myeloid progenitors were differentiated into osteoclasts or macrophages in the presence of $50 \mathrm{ng} / \mathrm{ml} \mathrm{M-CSF}$ with or without $50 \mathrm{ng} / \mathrm{ml}$ RANKL for $0-3$ days, followed by RNA extraction and reverse transcription as previously described (54-56). For quantitative reverse transcription (RT)-PCR analysis of the osteoclast-specific genes, the following TaqMan assays were used: Acp5 (TRAP; Taqman Mm00475698_m1), Ctsk (cathepsin K; Mm00484039_m1), Calcr (Calcitonin receptor; Mm00432271_m1), Nfatc1 (NFATc1; Mm00479445_m1), and Tm7sf4 (DC-STAMP; Mm04209235_m1) as previously described (54, 55). For assessment of Cre expression, the $5^{\prime}$ - TGACGGTGGGAGAATGTTAATC forward and 5' GCTACACCAGAGACGGAAATC reverse primers were used. Transcript levels relative to GAPDH were calculated using the comparative Ct method $(54,55)$.

\section{Sequencing of the Germline Syk ${ }^{\text {flox }}$ Allele}

To determine the exact sequence of the $S y k^{\text {flox }}$ allele, tail DNA was amplified using the $5^{\prime}$ - GCC CGT TCT GTG CCT ACT 
GG $-3^{\prime}$ forward and 5' - TAG CTA ACC AAA CCC ACG GC-3' reverse primers spanning the $5^{\prime}$ loxP site, or the $5^{\prime}$ - CCA AAG CGG AGT CCT CAC AT-3' forward and 5' - GTC GGT CCC ATC TTT CC $-3^{\prime}$ reverse primers spanning the $3^{\prime}$ loxP site. PCR products were then sent to Microsynth for sequencing and the obtained sequences were aligned with the genomic sequence of the wild type $S y k$ gene to obtain the sequence of the $S y k^{\text {flox }}$ allele.

\section{Genomic PCR Analysis}

Osteoclast cultures were washed at the indicated times after the start of RANKL treatment, followed by isolation of genomic DNA and PCR using standard procedures.

Two different PCR assays were performed on the genomic DNA of osteoclast cultures. In PCR 1, the $5^{\prime}$ - GCC CGT TCT GTG CCT ACT GG $-3^{\prime}$ forward primer (P fwd) was used along with the 5'- TAG CTA ACC AAA CCC ACG GC-3' reverse primer (P rev1) to separate the $S y k^{+}$and Syk flox alleles (234 and 349 bp product length, respectively). In PCR 2, the same P fwd forward primer was used with the $5^{\prime}$ - GTC GGT CCC ATC TTT $\mathrm{CC}-3^{\prime}$ reverse primer (P rev2) to separate the $S y k^{+}, S y k^{\text {flox }}$ and $S y k^{\Delta}$ alleles (1314, 1560 and 452 bp product length, respectively).

\section{Statistical Analysis}

Experiments were performed the indicated number of times. Diagrams show mean and SEM from the indicated number of independent experiments. Micro-CT measurements were analyzed by two-way (factorial) ANOVA with the presence/absence of Cre and the Syk genotype as the independent parameters. Other measurements were analyzed by one-way ANOVA followed by Tukey or Unequal n HSD post hoc test. In case of the kinetic analysis of osteoclast morphology, statistical analysis was performed on the area under the curve (AUC). $P$-values below 0.05 were considered statistically significant.

\section{RESULTS}

\section{The Effect of Osteoclast-Specific Syk Deletion on Trabecular Bone Architecture}

The $S y k^{-/-}$mutation causes perinatal lethality making it technically impossible to analyze the bone morphology of adult $S y k^{-/-}$mice. We decided to overcome that problem by generating lineage-specific Syk-deficient animals. As a first approach, we crossed mice in which the cDNA of the Cre recombinase has been inserted into the osteoclast-specific Ctsk gene (referred to as $C t s k^{\mathrm{Cre} /+}$ or Ctsk-Cre mice) (50) with mice carrying a floxed $S y k$ allele (referred to as $S y k^{\text {flox/flox }}$ mice) (49). The resulting $C t s k^{\mathrm{Cre} /+} S y k^{\text {flox/flox }}$ (referred to as $S y k^{\Delta \mathrm{OC}}$ ) mice are expected to have defective Syk expression in osteoclasts due to Cre-mediated excision and inactivation of the Syk gene.

We then subjected $S y k^{\Delta \mathrm{OC}}$ mice and the appropriate controls to micro-CT analysis of the distal femur. As shown in the longitudinal sections of the femurs of female mice in Figure 1A, the $S y k^{\Delta \mathrm{OC}}$ mutation strongly increased the density of the trabecular area compared to wild type mice, whereas no dramatic difference could be observed in Ctsk-Cre or $S y k^{\text {flox/flox }}$ animals. Analysis of representative cross-sections of male or female mouse femurs also showed increased trabecular density in $S y k^{\Delta \mathrm{OC}}$ but not in Ctsk-Cre or $S y k^{\text {flox/flox }}$ animals, particularly in the case of female mice (Figure 1B). The increased trabecular density was also evident in three-dimensional reconstitution of an axial cylinder within the trabecular area of the femurs (Figure 1C).

We also processed micro-CT images for quantitative analysis, incorporating data from the entire trabecular space within a defined distance range from the distal femoral growth plate. As shown in Figure 2, the percent bone volume (BV/TV) was strongly increased in $S y k^{\Delta \mathrm{OC}}$ mice, whereas no substantial difference could be observed in Ctsk-Cre or $S y k^{\text {flox/flox }}$ mice. Male wild type mice had an $\sim 2.8$-fold higher $(10.8 \%)$ basal percent bone volume (BV/TV) than their female counterparts (3.9\%). However, the increase in BV/TV in $S y k^{\Delta \mathrm{OC}}$ over wild type mice was more robust in female (4.4-fold) than in male (1.8-fold) animals (Figure 2). We have also performed statistical analysis by two-way (factorial) ANOVA which determines the interaction of the two (Ctsk-Cre and $S y k^{\text {flox/flox }}$ ) mutations, i.e., whether the co-existence of the two mutation in the $S y k^{\Delta \mathrm{OC}}$ resulted in a statistically significant difference beyond an additive effect. That analysis revealed a significant increase of the BV/TV values both in male $(p=0.028)$ and, especially, in female $(p=0.00005)$ mice.

Further quantitative (Figure 2) and statistical (two-way ANOVA) analysis of the trabecular bone revealed a higher trabecular number in $S y k^{\Delta O C}$ mice $(p=0.0069$ and 0.00001 for males and females, respectively), whereas no consistent change was observed in the trabecular thickness of the same animals ( $p=$ 0.85 and 0.87 for males and females, respectively). In agreement with the increased trabecular number, trabecular separation was reduced in $S y k^{\Delta O C}$ mice $(p=0.00032$ and 0.0011 for males and females, respectively).

Taken together, our results indicate that osteoclast-specific deletion of Syk causes increased bone trabecular mass primarily due to increased bone trabecular number rather than a higher trabecular thickness. However, the phenotype observed in $S y k^{\triangle \mathrm{OC}}$ mice (Figure 2) appeared to be less dramatic than that reported for Tyrobp ${ }^{-/-}$Fcer $1 g^{-/-}$double knockout mice lacking both the DAP12 and FcR $\gamma$ ITAM-containing adapter molecules which were previously proposed to signal through Syk $(42,43,57)$.

\section{The Effect of Hematopoietic Deletion of Syk on Trabecular Bone Architecture}

The apparently less severe bone phenotype of $S y k^{\Delta \mathrm{OC}}$ mice compared to Tyrobp ${ }^{-/-}{\text {Fcer } 1 g^{-/-}}^{(\mathrm{DAP} 12 / \mathrm{FcR} \gamma}$ double knockout) animals $(42,43,57)$ could either be due to a less critical role for Syk in in vivo bone homeostasis or the less complete deletion of Syk in $S y k^{\Delta \mathrm{OC}}$ animals. To test this latter possibility, we turned to mice with Syk deficiency in the entire hematopoietic compartment due to deletion by the Vav-Cre transgene which causes Cre expression during the early stages of hematopoiesis (51). Accordingly, we subjected Vav-Cre $S y k^{\text {flox/flox }}$ (referred to as $S y k^{\Delta \text { Haemo }}$ ) mice and appropriate controls to microCT analysis of the distal femur.

As shown in Figure 3A, Syk deletion in the entire hematopoietic compartment by the $S y k^{\Delta \text { Haemo }}$ mutation caused a very strong increase in trabecular density in the 

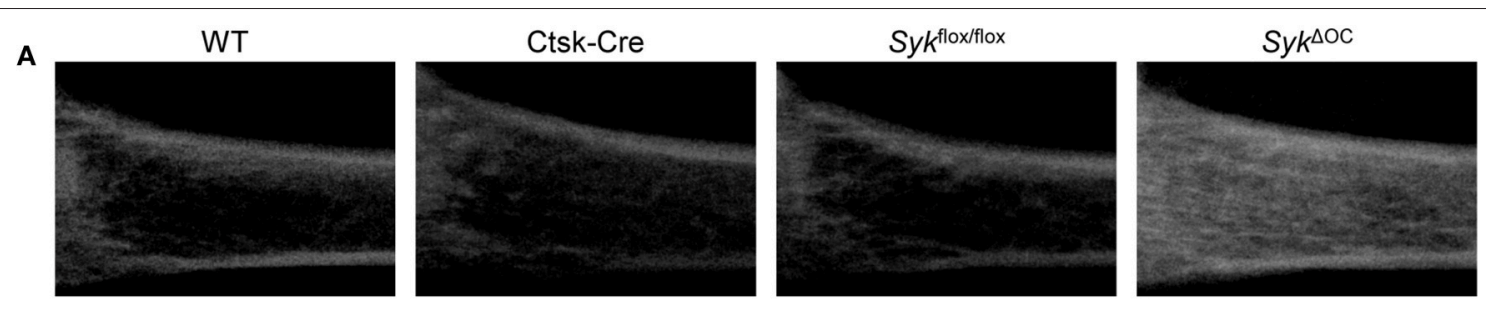

B
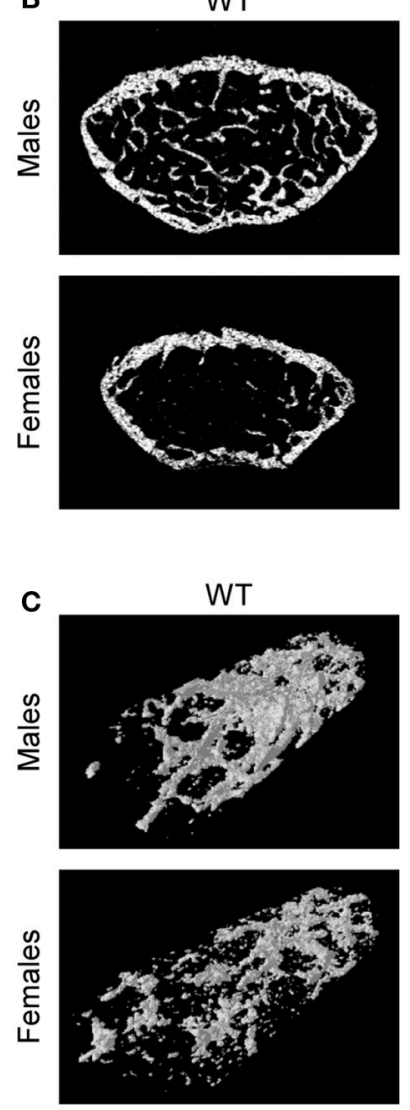

Ctsk-Cre
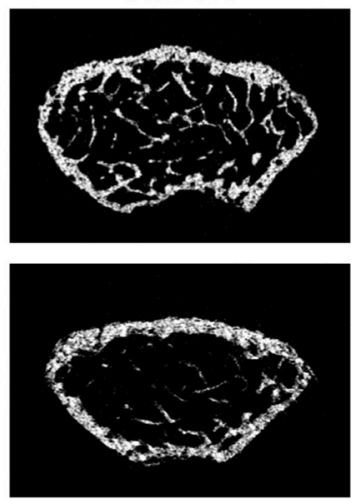

Ctsk-Cre
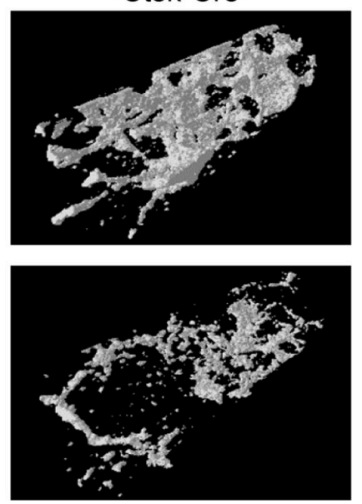
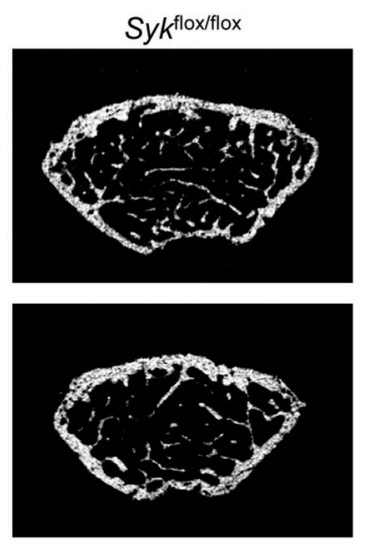

Sy $k^{\text {flox/flox }}$
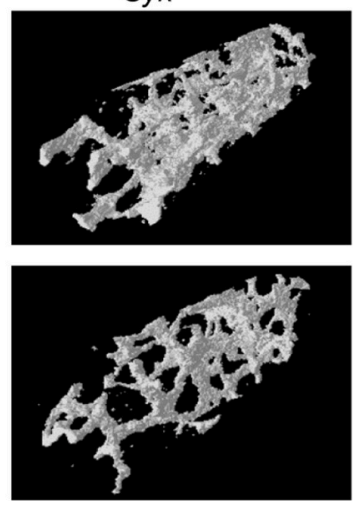
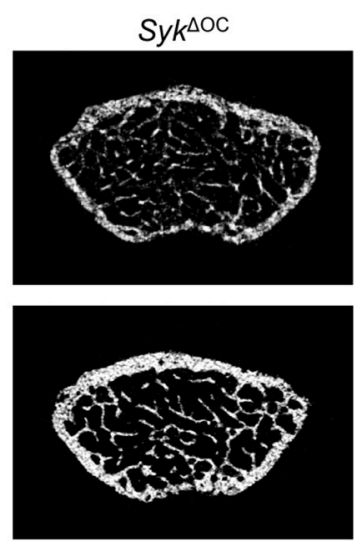

Syk ${ }^{\Delta O C}$
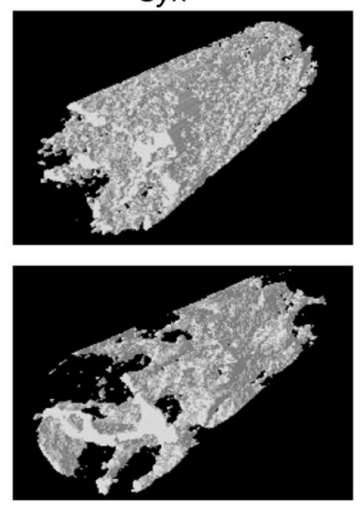

FIGURE 1 | Micro-CT analysis of osteoclast-specific Syk-deficient mice. Representative micro-CT images of the femurs of 9-week-old mice of wild type (WT) and the indicated mutant mice. (A) Longitudinal sections of the femur of female mice. (B) Cross-sections of the femur of male or female mice. (C) 3D reconstitution of an axial cylinder of the trabecular area of the distal metaphysis of femurs of male or female mice. Images are representative of micro-CT analysis of 5 mice per gender and genotype.

longitudinal sections of the femurs of female animals, whereas no substantial changes were observed in Vav-Cre or Syk flox/flox mice. An increased trabecular density in $S y k^{\Delta \text { Haemo }}$ mutants could also be observed in cross-sections of the distal femurs of male and, in particular, female mice, whereas no obvious differences could be seen in Vav-Cre or $S y k^{\text {flox/flox }}$ animals (Figure 3B). Three-dimensional reconstitution of a trabecular area cylinder also showed visible increases in the trabecular density in $S y k^{\Delta \text { Haemo }}$ animals (Figure 3C).

Further quantitative analysis of the microCT data (Figure 4) indicated a strongly increased percent bone volume (BV/TV) in $S y k^{\Delta \text { Haemo }}$ mice in both male and female animals.
Importantly, BV/TV values in $S y k^{\Delta \text { Haemo }}$ mice appeared to be substantially higher than corresponding $S y k^{\Delta \mathrm{OC}}$ animals (compare Figures 2, 4). On the other hand, similar to the $S y k^{\Delta \mathrm{OC}}$ results, the $\mathrm{BV} / \mathrm{TV}$ fold increase in $S y k^{\Delta \text { Haemo }}$ over wild type animals was higher in females (7.9-fold) than in males (4.0-fold), again primarily due to the higher basal values in male wild type mice. Statistical analysis by two-way ANOVA revealed a highly significant interaction between the effects of the Vav-Cre and $S y k^{\text {flox/flox }}$ mutations $(p=0.00032$ and 0.00003 for males and females, respectively), indicating that Cre-mediated deletion of Syk in $S y k^{\Delta \text { Haemo }}$ mice strongly increases trabecular bone mass. 


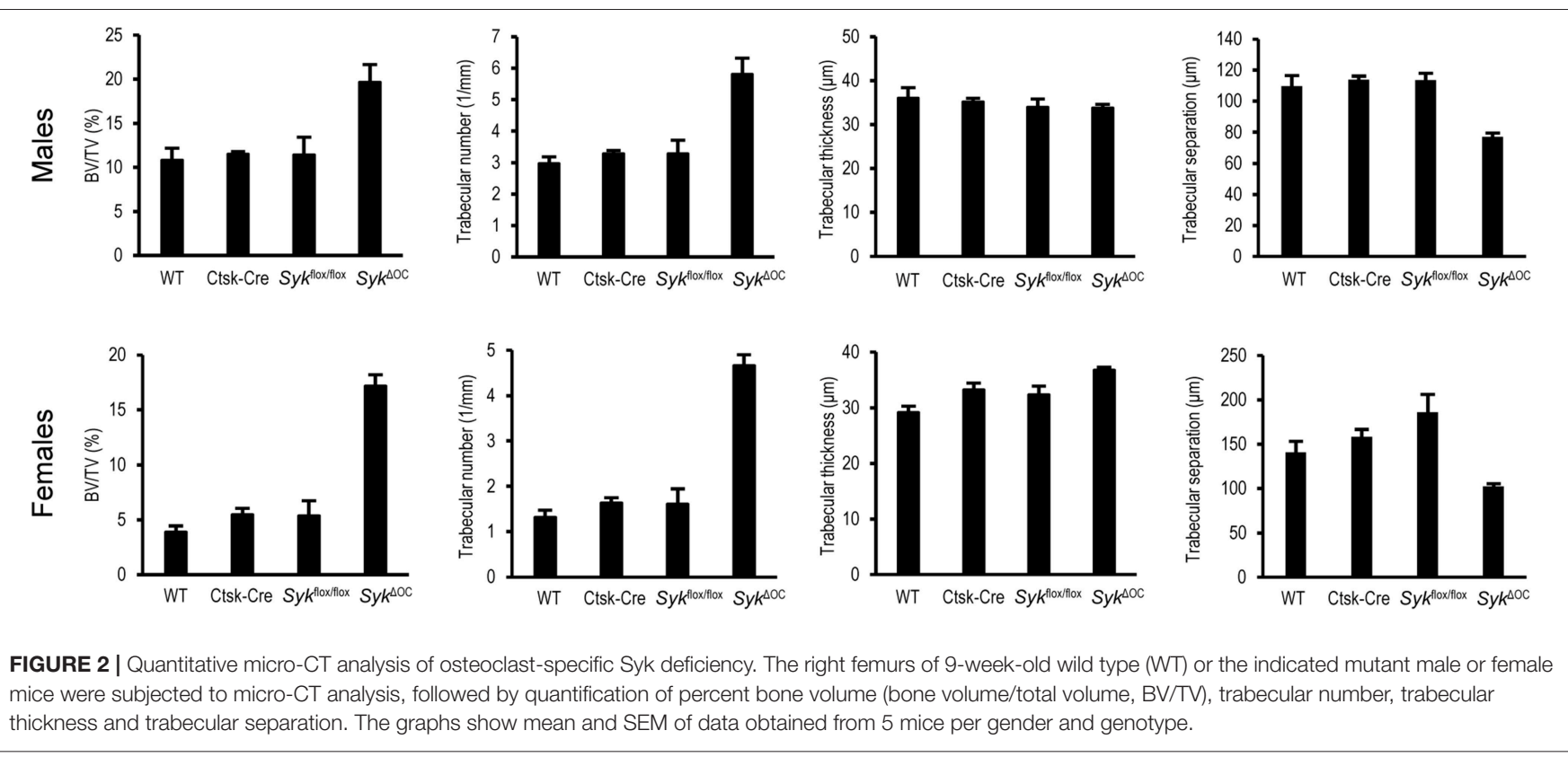

Further quantitative assessment (Figure 4) and statistical analysis (two-way ANOVA) revealed that, similar to the $S y k^{\Delta \mathrm{OC}}$ mice, the increased trabecular bone volume was primarily due to an increased trabecular number $(p=0.0010$ and 0.00001 for males and females, respectively), rather than significant changes in trabecular thickness $(p=0.31$ and 0.61 for males and females, respectively). Trabecular separation was also reduced in $S y k^{\Delta \text { Haemo }}$ mice $(p=0.0045$ and 0.0071 for males and females, respectively).

Taken together, early deletion of Syk in the entire hematopoietic system results in dramatic increase in the mineralized trabecular bone mass, indicating a critical role for Syk in in vivo bone homeostasis. The bone phenotype seen in $S y k^{\Delta \text { Haemo }}$ mice is grossly comparable to that reported for Tyrobp ${ }^{-/-}$Fcer1g $g^{-/-}$(DAP12/FcR $\gamma$ double knockout) animals $(42,43,57)$, raising the possibility that the majority of DAP12/FcR $\gamma$ signals proceeds through Syk in live mice. However, the $30-45 \% \mathrm{BV} / \mathrm{TV}$ values observed in $S y k^{\Delta \text { Haemo }}$ mice are substantially higher than the corresponding values (15-20\%) in $S y k^{\triangle \mathrm{OC}}$ animals, raising the possibility that the lower values in the latter mutants may be due to incomplete deletion of Syk by Cre expression from the Ctsk-Cre mutation.

\section{Bone Histological Analysis}

We have also performed histological analysis of the distal femur of wild type, $S y k^{\Delta \mathrm{OC}}$ or $S y k^{\Delta \text { Haemo }}$ mice. As shown in Figure 5A, a much more dense trabecular network was seen in $S y k^{\Delta \mathrm{OC}}$ and, especially, $S y k^{\Delta \text { Haemo }}$ mice than in wild type animals. Again, the difference was more pronounced in female mice because of the lower trabecular density in female than in male mice in the wild type cohorts.

To test the presence of mature osteoclasts on the trabecular bone surface, we have performed immunofluorescence staining of bone sections for calcitonin receptor, an osteoclast-specific differentiation marker. As shown in Figure 5B, calcitonin receptor signals were evident on the lining of trabecular rods (dark areas) in wild type sections. Similar signals were also seen but at substantially lower numbers in $S y k^{\Delta \mathrm{OC}}$ sections, whereas no such signals were seen in $S y k^{\Delta \text { Haemo }}$ sections (Figure $5 B$ ). Those results suggest that the number of calcitonin receptorpositive osteoclasts is reduced in $S y k^{\Delta \mathrm{OC}}$ and, especially, in Syk $k^{\Delta \text { Haemo }}$ mice.

\section{In vitro Osteoclast Development in Lineage-Specific Syk Mutants}

We next tested in vitro development of osteoclasts from wild type, $S y k^{\Delta \mathrm{OC}}$ or $S y k^{\Delta \mathrm{Haemo}}$ bone marrow cells in the presence of recombinant M-CSF and RANKL cytokines. Bone marrow cells were first cultured for 2 days in low $(10 \mathrm{ng} / \mathrm{ml})$ M-CSF and non-adherent cells (referred to as myeloid progenitors) were then cultured in the presence of $50 \mathrm{ng} / \mathrm{ml} \mathrm{M-CSF}$ and $50 \mathrm{ng} / \mathrm{ml}$ RANKL. Osteoclast development was then tested by assessing cell morphology and positive histochemical staining for the osteoclast-specific TRAP enzyme.

As shown in Figure 6A, no TRAP-positive multinuclear cells (osteoclasts) were seen 2 days after addition of RANKL to the cultures. However, osteoclasts started to appear in wild type cultures on day 3 and formed very large multinucleated TRAP-positive cells 3.5 days after the initial RANKL treatment. Some osteoclasts also formed in $S y k^{\Delta \mathrm{OC}}$ cultures, though they were much smaller in size and failed to fuse into very large cells even by 3.5 days after RANKL treatment (Figure 6A). On the other hand, practically no osteoclasts (multinucleated TRAP-positive cells) could be observed in $S y k^{\Delta \text { Haemo }}$ cultures (Figure 6A).

We have also quantitated the extent of in vitro osteoclast formation. To this end, we have counted the number of osteoclasts (defined as TRAP-positive cells with 3 or more 

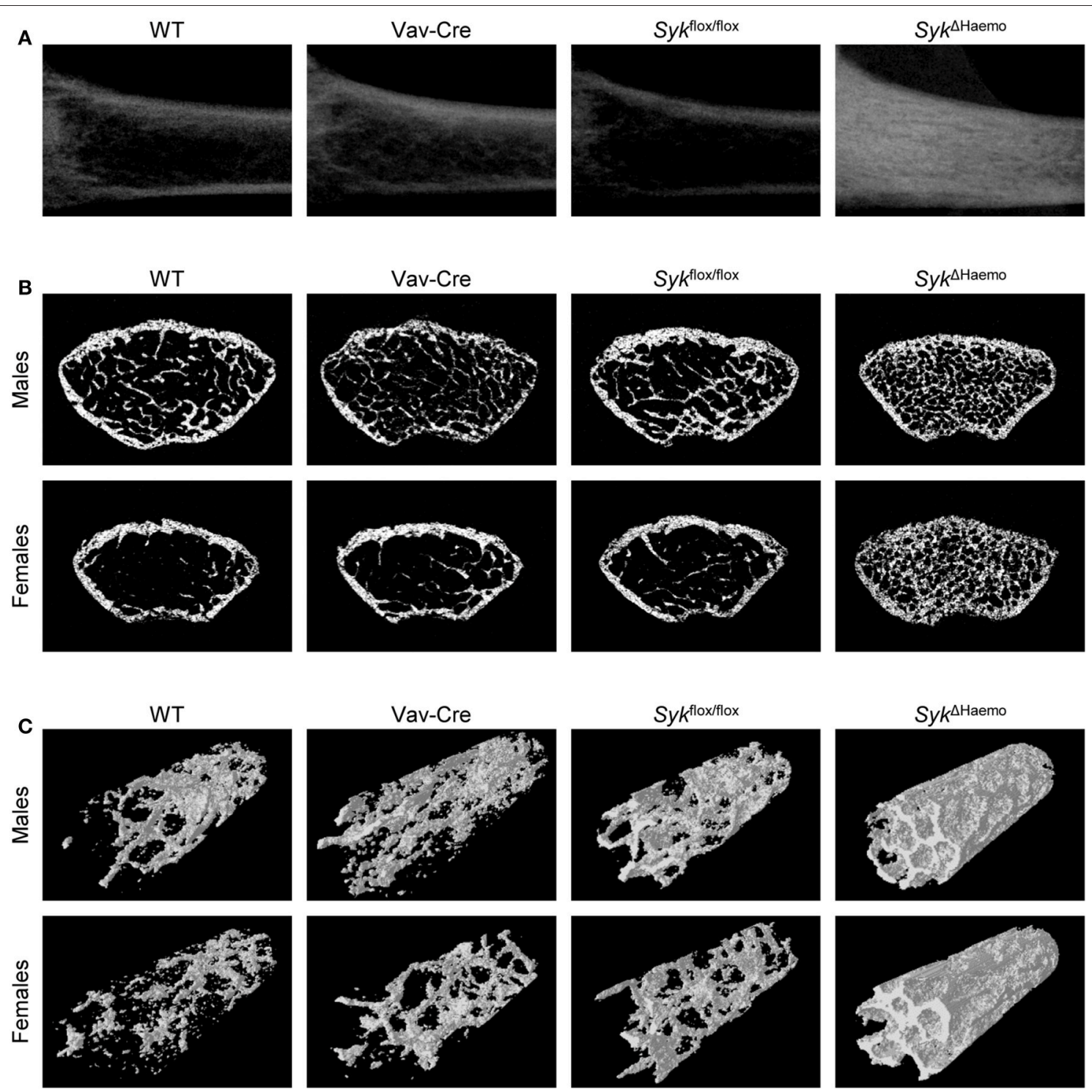

FIGURE 3 | Micro-CT analysis of hematopoietic Syk-deficient mice. Representative micro-CT images of the femurs of 9-week-old mice of wild type (WT) and the indicated mutant mice. (A) Longitudinal sections of the femur of female mice. (B) Cross-sections of the femur of male or female mice. (C) 3D reconstitution of an axial cylinder of the trabecular area of the distal metaphysis of femurs of male or female mice. Images are representative of $5-7$ mice per gender and genotype. WT samples are identical to those shown in Figure $\mathbf{1 .}$

nuclei; Figure 6B) and calculated the percent of the culture area covered by the osteoclasts (Figure 6C). Though the two different quantification approaches were related to each other, they also complemented each other, since later stages of osteoclast development may lead to the emergence of very large osteoclasts which occupy large culture areas but are small in numbers (as seen in the last two images in wild type cultures in Figure 6A).

As seen in Figures 6B,C, there were practically no osteoclasts in any of the cultures 2 days after the initial RANKL addition. However, osteoclasts rapidly emerged afterwards in wild type cultures, reaching a maximum number 1 day later. The area covered by wild type osteoclasts increased further in the next
$12 \mathrm{~h}$, even though the number of osteoclasts started to decline, indicating the fusion of the cells into a few very large osteoclasts in this final stage of osteoclast development (Figures 6B,C). The number of osteoclasts also increased in $S y k^{\Delta \mathrm{OC}}$ cultures and was temporarily even comparable to that of wild type osteoclasts (Figure 6B). However, those $S y k^{\Delta \mathrm{OC}}$ osteoclasts covered a significantly smaller area than in wild type cultures throughout the experiments (Figure 6C), which was in line with the smaller size of $S y k^{\triangle \mathrm{OC}}$ osteoclasts in Figure 6A. On the other hand, again in agreement with the photomicrographs in Figure 6A, practically no osteoclasts could be identified in $S y k^{\Delta \text { Haemo }}$ cultures (Figures 6B,C). 


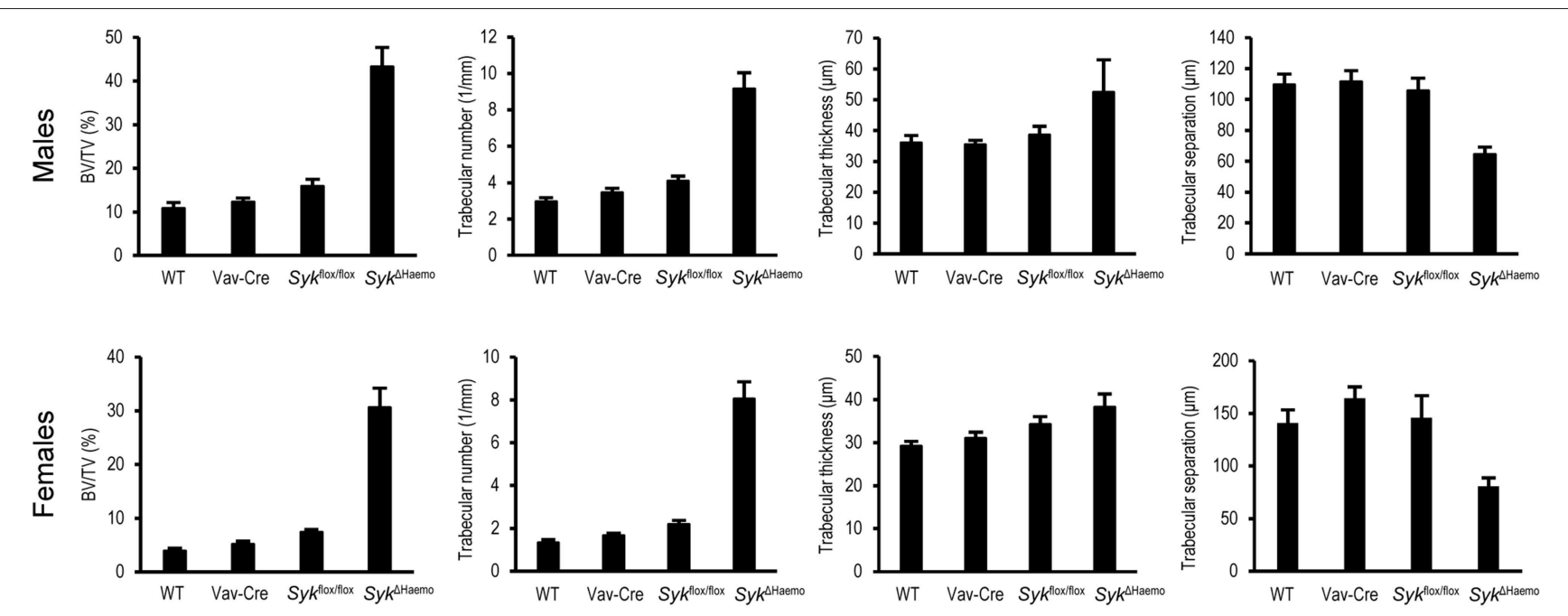

FIGURE 4 | Quantitative micro-CT analysis of hematopoietic Syk deficiency. The right femurs of 9-week-old wild type (WT) or the indicated mutant male or female mice were subjected to micro-CT analysis, followed by quantification of percent bone volume (bone volume/total volume, BV/TV), trabecular number, trabecular thickness and trabecular separation. The graphs show mean and SEM of data obtained from 5-7 mice per gender and genotype. WT values are identical to those shown in Figure 2.

We have also performed more detailed statistical analyses (one-way ANOVA) of the area under the curve (AUC) from data presented in Figures 6B,C. In case of the number of osteoclasts (Figure 6B), no statistical difference was seen between the wild type and $S y k^{\Delta \mathrm{OC}}$ cultures $(p=0.12)$, likely reflecting the fact that the osteoclast numbers only declined on the last day in the $S y k^{\triangle \mathrm{OC}}$ samples (Figure 6B). However, the number of osteoclasts in the $S y k^{\Delta \text { Haemo }}$ cultures was statistically highly significantly reduced compared to wild type ones $(p=0.0013)$. The total area covered by osteoclasts was highly significantly reduced both by the $S y k^{\Delta \mathrm{OC}}(p=0.00058)$ and the $S y k^{\Delta \text { Haemo }}$ $(p=0.00024)$ mutations.

The above results confirm prior studies indicating a critical role for Syk during in vitro osteoclast development $(40,42,44)$. On the other hand, they also indicate an incomplete osteoclast developmental defect in $S y k^{\Delta \mathrm{OC}}$ cultures (as opposed to the complete defect in $S y k^{\Delta \text { Haemo }}$ ones), suggesting incomplete deletion of Syk in $S y k^{\Delta \mathrm{OC}}$ mutants.

\section{Analysis of the in vitro Resorptive Activity of Osteoclasts}

We also attempted to test the in vitro resorbing capacity of osteoclasts. To this end, myeloid precursors were plated on an artificial hydroxyapatite layer and cultured in the presence of M-CSF and RANKL ( $50 \mathrm{ng} / \mathrm{ml}$ each) for 7 days, followed by assessment of hydroxyapatite resorption by dark field microscopy. It should be noted that this assay measures the combined effect of both osteoclast development and osteoclastmediated matrix resorption.

As shown in Figure 7A, wild type osteoclast cultures were able to resorb substantial areas of the hydroxyapatite layer (resorbed areas show a dark appearance). In contrast, only small areas of resorption could be observed in $S y k^{\Delta \mathrm{OC}}$ cultures and no resorption was seen in $S y k^{\Delta \text { Haemo }}$ cultures (Figure 7A). Quantification of the resorbed area revealed $\sim 40 \%$ resorption in wild type cultures, which was strongly reduced by the $S y k^{\Delta \mathrm{OC}}$ and completely eliminated by the $S y k^{\Delta \text { Haemo }}$ mutations (Figure $7 \mathbf{B}$ ). Statistical analysis (one-way ANOVA) revealed highly significant reduction of the resorption activity both by the $S y k^{\Delta \mathrm{OC}}$ $(p=0.00040)$ and the $S y k^{\Delta \text { Haemo }}(p=0.00038)$ mutations.

These results confirm an important role for Syk in the development and/or function of bone-resorbing osteoclasts (42), and also indicate slight differences between the $S y k^{\Delta \mathrm{OC}}$ and Syk $k^{\Delta \text { Haemo }}$ mutations.

\section{Analysis of Osteoclast-Specific Gene Expression}

We next tested the changes of osteoclast-specific gene expression in osteoclast cultures from the different genotypes. We have also tested additional control macrophage cultures generated under identical conditions except that RANKL treatment was omitted. As shown in Figure 8, the expression of DC-STAMP (encoded by the Tm7sf4 gene), TRAP (Acp5), calcitonin receptor (Calcr), NFATc1 (Nfatc1) and cathepsin K (Ctsk) mRNA strongly increased upon osteoclastic differentiation whereas no such increase could be observed in parallel macrophage cultures. The expression of all those genes were reduced in both the $S y k^{\Delta O C}$ and $S y k^{\Delta \text { Haemo }}$ cultures (Figure 8), though the defect ranged from a moderate $(\mathrm{Tm} 7 \mathrm{sf4}$ ) to a very strong ( $\mathrm{Calcr}$ ) reduction. It should also be noted that the reduced expression of Ctsk in $S y k^{\triangle \mathrm{OC}}$ samples is likely partially due to the inactivation of one of the two alleles of the Ctsk gene by the Ctsk-Cre $\left(C t s k^{\mathrm{Cre} /+}\right)$ mutation present in those cells. Taken together, gene expression data indicate a role for Syk in regulation of osteoclast-specific gene expression. 

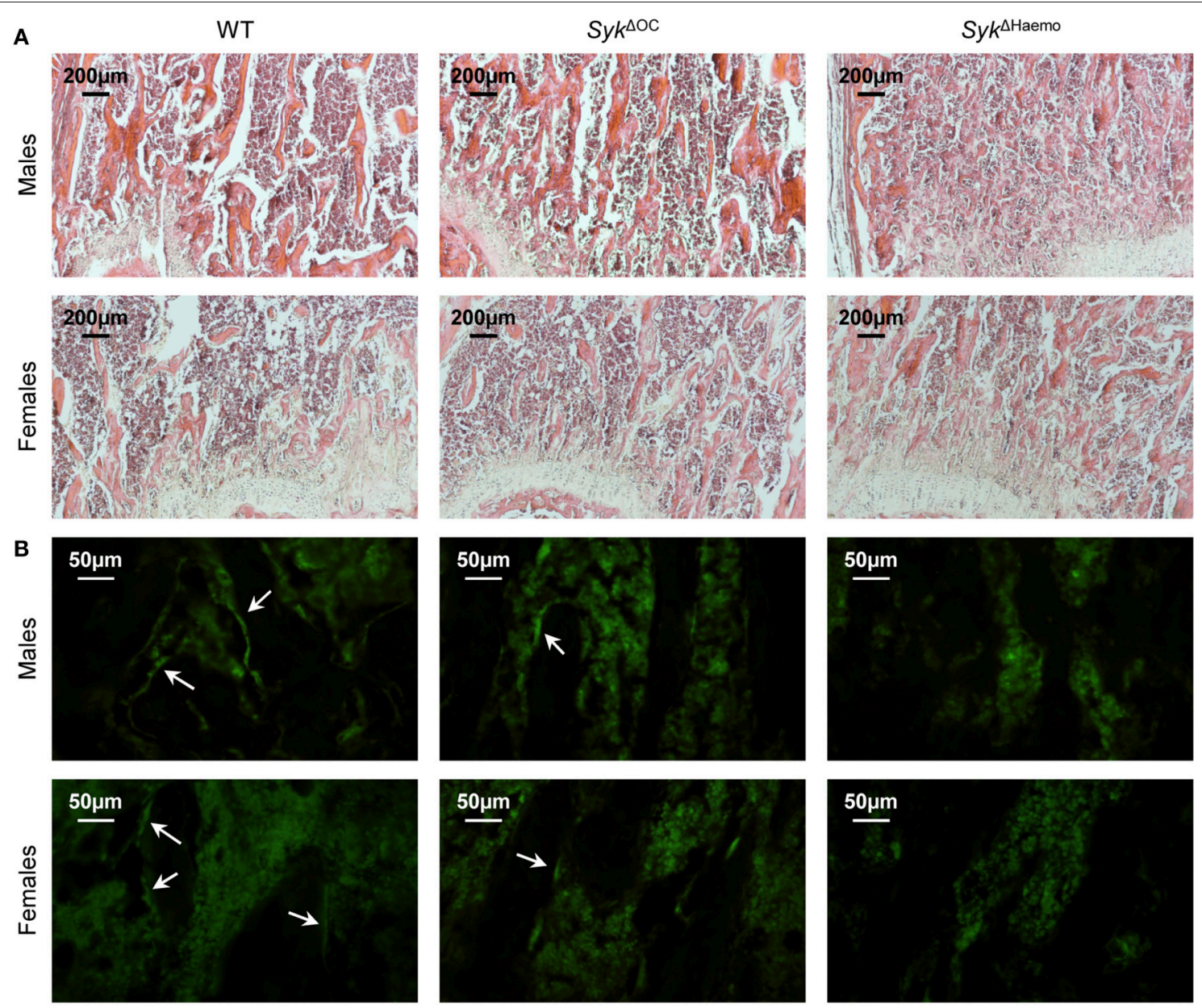

FIGURE 5 | Histological and immunofluorescence analysis of osteoclast-specific and hematopoietic Syk deficiency. Representative photomicrographs of the trabecular area of the femurs of 9-week-old wild type (WT), Syk ${ }^{\Delta O C}$ or Syk $\Delta$ Haemo mice. (A) Haematoxylin and eosin staining; original magnification $\times 10$. (B) Calcitonin receptor immunostaining; original magnification $\times 40$. Arrows indicate calcitonin receptor-positive bone lining cells (likely osteoclasts). Images are representative of 3 mice per gender and genotype.

\section{Analysis of Syk Protein Levels in Osteoclast Cultures}

The different severity of the in vivo bone phenotypes (Figures 1-5) and in vitro osteoclast developmental defect (Figure 6) between the $S y k^{\Delta \mathrm{OC}}$ and $S y k^{\Delta H_{a e m o}}$ mutants raised the possibility that Syk is incompletely deleted from $S y k^{\Delta \mathrm{OC}}$ osteoclasts. To test this more specifically, we performed Western Blot analysis of Syk expression during osteoclastic and macrophage differentiation of wild type and mutant bone marrow cells.

As shown in Figure 9A, Syk was present in all wild type cultures and its expression slightly even increased during osteoclast differentiation from wild type myeloid progenitors. Importantly, Syk was also present throughout the assessment period in $S y k^{\Delta \mathrm{OC}}$ cultures (Figure 9A). On the other hand, Syk was completely absent throughout the entire observation period in $S y k^{\Delta \text { Haemo }}$ cultures (Figure 9A). Semiquantitative analysis of the Western blot samples (Figure 9B) confirmed the presence of
Syk in all wild type and $S y k^{\Delta \mathrm{OC}}$ but not in $S y k^{\Delta \text { Haemo }}$ samples. Although there was a tendency of reduced Syk expression in $S y k^{\triangle \mathrm{OC}}$ osteoclasts as compared to wild type osteoclasts, this difference was not statistically significant, indicating that the $S y k^{\Delta \mathrm{OC}}$ mutation is not able to reduce Syk expression at the overall cell population level.

The above results provided direct evidence supporting our assumption that Syk is incompletely deleted from $S y k^{\Delta \mathrm{OC}}$ but it is completely absent from $S y k^{\Delta \text { Haemo }}$ osteoclast cultures.

\section{Genetic Analysis of Syk Deletion During Osteoclastogenesis}

One of the possible explanations for the observed differences between the $S y k^{\Delta \mathrm{OC}}$ and $S y k^{\Delta \text { Haemo }}$ mutants is that Cre expression from the Ctsk-Cre mutation occurs at a late stage of osteoclast development which, combined with the potentially long survival of the Syk protein, leads to reduction of Syk protein levels only at a late stage when osteoclast development has already 
A
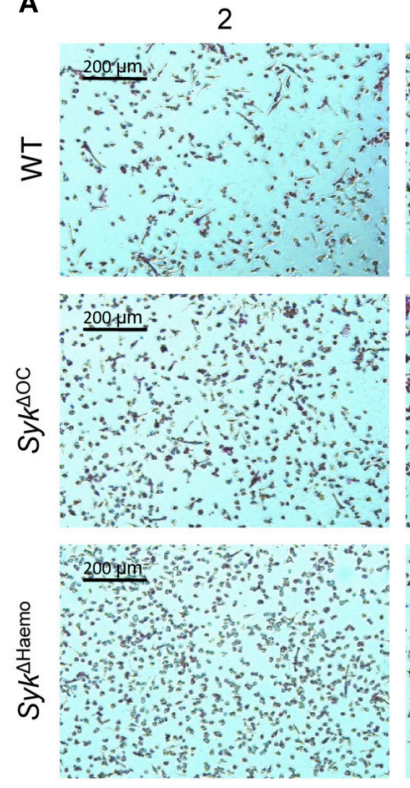

RANKL treatment (days)

2.5
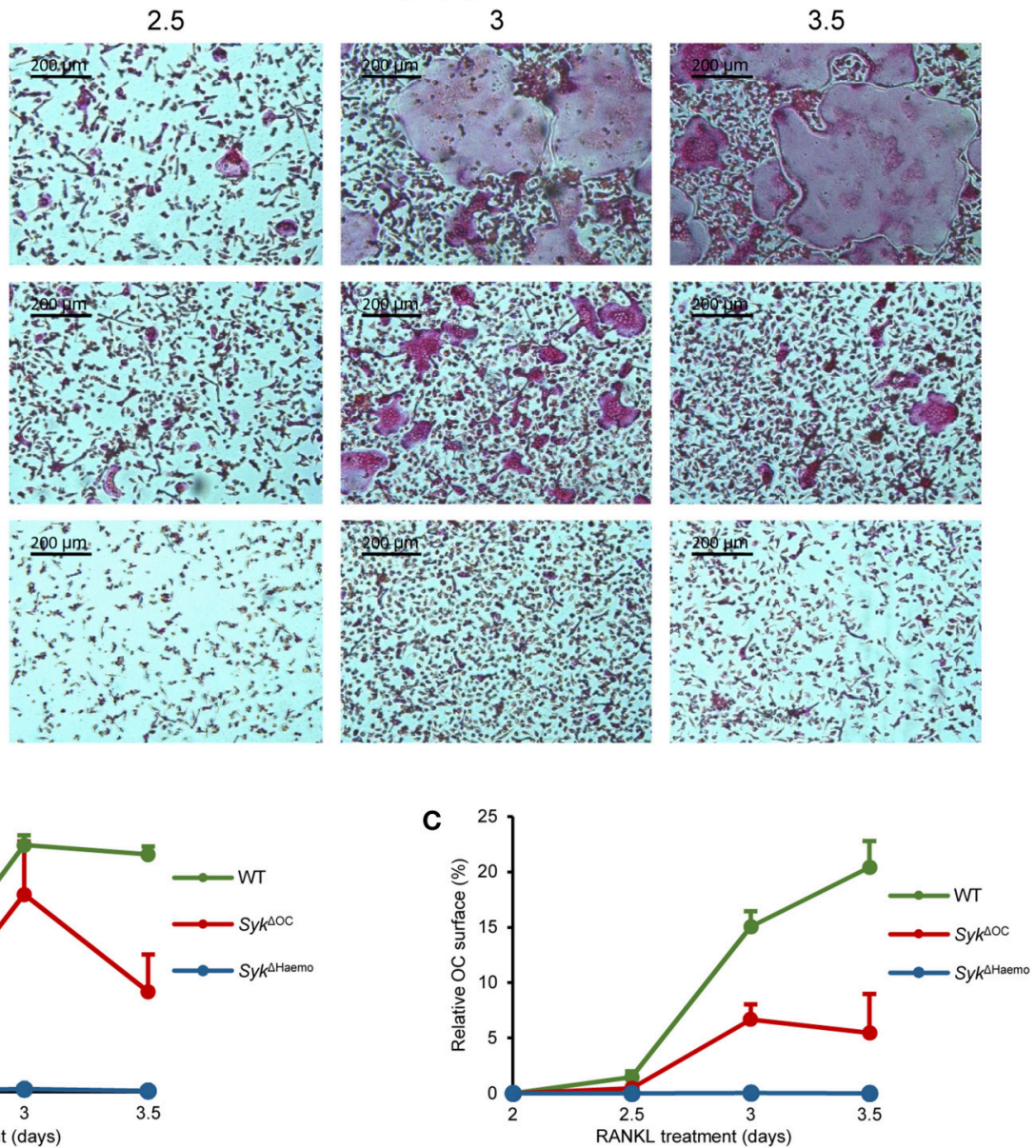

FIGURE 6 | Analysis of in vitro osteoclast development. Bone marrow-derived myeloid progenitors from wild type (WT), Syk ${ }^{\Delta O C}$ or Syk ${ }^{\Delta H a e m o}$ mice were cultured in the presence of $50 \mathrm{ng} / \mathrm{ml}$ M-CSF and $50 \mathrm{ng} / \mathrm{ml}$ RANKL for the indicated times, followed by staining for tartrate-resistant acid phosphatase (TRAP). (A) Representative images of TRAP-stained cultures. (B) Quantification of the number of osteoclasts (TRAP-positive cells with 3 or more nuclei) in the different cultures. (C) The area covered by osteoclasts in the different cultures (in \% of the total culture area). Images are representative of, and bar graphs show mean and SEM from, 3 independent experiments.

B

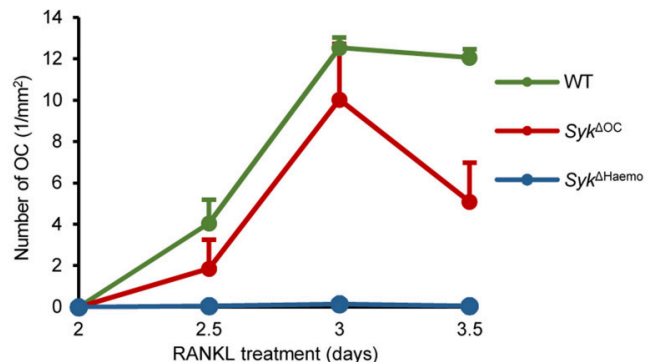

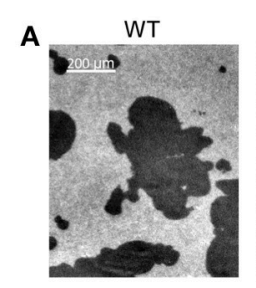
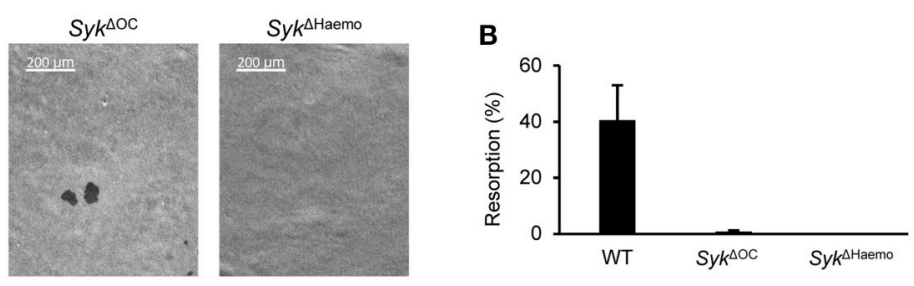

FIGURE 7 | Analysis of the in vitro resorptive function of osteoclasts. Bone marrow-derived myeloid progenitors from wild type (WT), Syk ${ }^{\Delta O C}$ or Syk ${ }^{\Delta H_{1}}$ aemo mice were cultured in the presence of $50 \mathrm{ng} / \mathrm{ml} \mathrm{M-CSF}$ and $50 \mathrm{ng} / \mathrm{ml}$ RANKL for 7 days on an artificial hydroxyapatite layer. (A) Representative dark-field microscopic images of resorption pits (dark areas). (B) Quantification of the resorption area (in percent of the total area). Images are representative of, and bar graphs show mean and SEM from, 3 independent experiments.

occurred. The fact that the substantial expression of the Ctsk gene (encoding for cathepsin $\mathrm{K}$ ) begins at 2 days, and is maximal at 3 days after RANKL treatment (Figure 8) $(54,55)$ would be in line with that possibility.
As a first approach to address the above issue, we performed qPCR-based analysis of the expression the Cre recombinase in osteoclasts and macrophages from the different genotypes (Figure 10A). As expected, no Cre expression could be observed 

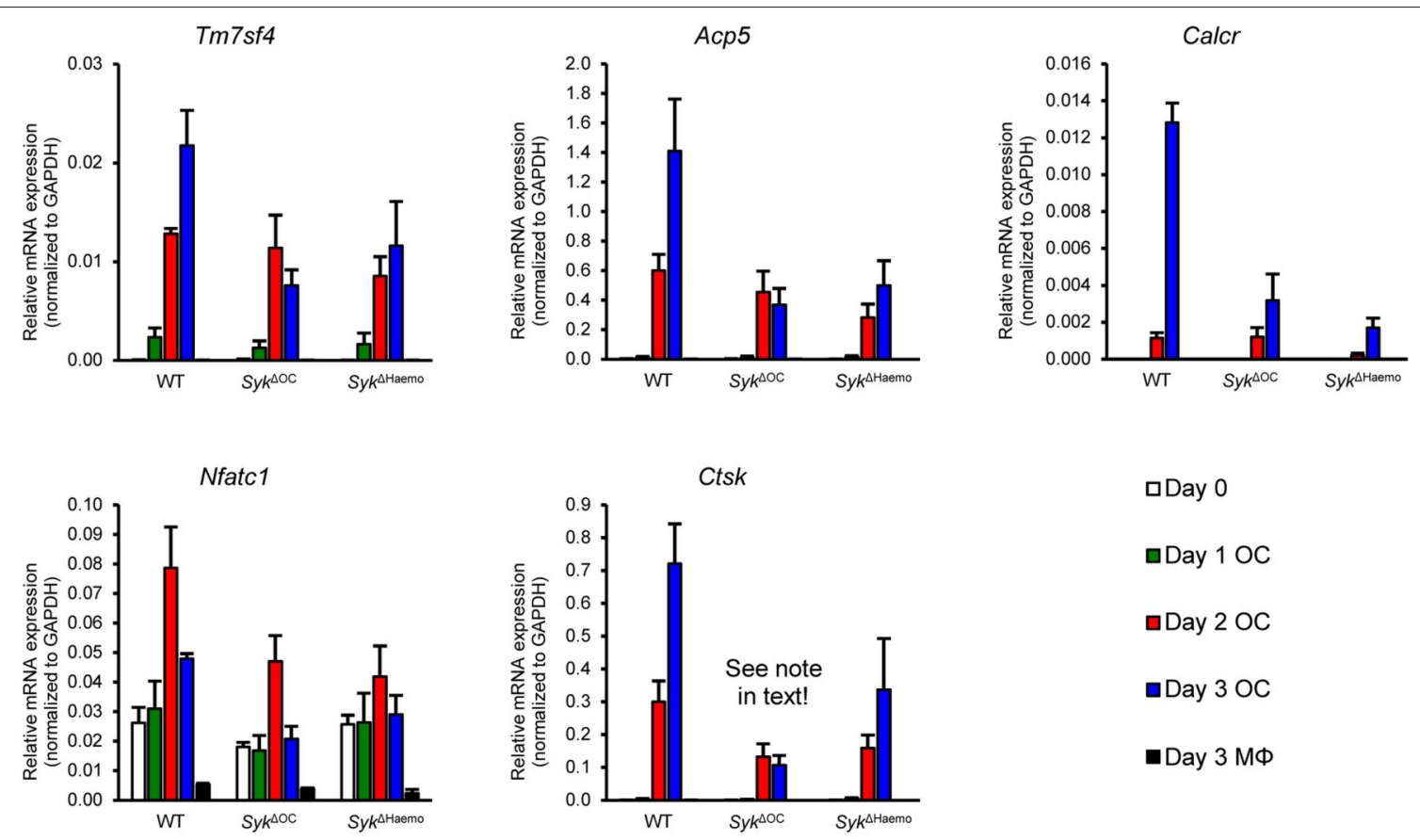

口Day 0

aDay 1 OC

๑Day 2 OC

-Day 3 OC

-Day 3 MФ

FIGURE 8 | Analysis of osteoclast-specific gene expression. Gene expression in bone marrow-derived cells from wild type (WT), Syk ${ }^{\Delta O C}$ or Syk $\Delta$ Haemo mice cultured for 0-3 days in the presence of $50 \mathrm{ng} / \mathrm{ml}$ M-CSF with (osteoclasts; OC) or without (macrophages; M $\Phi$ ) $50 \mathrm{ng} / \mathrm{ml}$ RANKL. The expression of the Tm7sf4, Acp5, Calcr, Nfatc1, and Ctsk genes (encoding for DC-STAMP, TRAP, Calcitonin receptor, NFATc1, and Cathepsin K, respectively) were determined by quantitative RT-PCR and normalized to Gapdh. Bar graphs show mean and SEM from 3 independent experiments.

in wild type cultures. Somewhat surprisingly, no Cre mRNA could be detected in $S y k^{\Delta \text { Haemo }}$ cultures either which, together with the complete absence of Syk protein in those cultures (Figure 9) suggests that the Vav-Cre transgene is activated at an early stage of hematopoiesis but it is silenced at the stage of myeloid differentiation tested in our experiments. On the other hand, Cre expression could be readily observed in Syk ${ }^{\triangle \mathrm{OC}}$ osteoclast but not macrophage cultures (Figure 10A). Importantly, substantial Cre expression in $S y k^{\Delta \mathrm{OC}}$ osteoclasts was first observed 2 days after the initial RANKL treatment, and continued afterwards. Given that a longer time may be needed to the effective deletion of both $S y k$ alleles, the supposedly partial deletion efficacy of the Ctsk-Cre transgene and that the Syk mRNA and protein likely does not immediately disappear after the Cre-mediated inactivation of the $S y k$ gene, these results are in line with the continued presence of Syk in $S y k^{\Delta \mathrm{OC}}$ osteoclasts beyond 2 days after the initial RANKL administration (Figure 9).

As a more direct approach to test Cre-mediated deletion of Syk in our osteoclast cultures, we decided to perform PCRbased analysis of the Syk genomic locus from the cells of our various genotypes. To this end, we first amplified and sequenced the genomic DNA around the two loxP insertion sites, which was used along with the publicly available mouse genomic sequence and the original description of the $S y k^{\text {flox }}$ mutation (50) to reconstruct the entire sequence of the Syk $k^{\text {flox }}$ allele (Supplementary Figure 1). The organization of the $S y k^{+}$(wild type), Syk flox and $S y k^{\Delta}$ (result of Cre-mediated deletion) alleles is shown in Supplementary Figure 2, indicating the inserted loxP and other sequences, as well as the sites and results of Cre-mediated recombination. Based on this organization, we have designed two PCR protocols (termed PCR 1 and PCR 2) to amplify specific alleles from genomic DNA (Supplementary Figure 2). PCR 1 (Figure 10B and Supplementary Figure 2) was our standard genotyping PCR protocol using the $\mathrm{P}$ fwd and $\mathrm{P}$ revl primer pair, and was able to distinguish between the $S y k^{+}$and the $S y k^{\text {flox }}$ allele, based on the increased length of the PCR product caused by the $115 \mathrm{bp}$ insertion during the generation of the $S y k^{\text {flox }}$ allele (49). However, PCR 1 was not able to detect the deleted $\left(S y k^{\Delta}\right)$ allele because the sequence corresponding to the $\mathrm{P}$ rev1 primer was deleted during Cre-mediated excision of the floxed sequences from the $S y k^{\text {flox }}$ allele (Supplementary Figure 2). Therefore, we designed a novel PCR protocol (PCR 2; Figure 10C and Supplementary Figure 2) using the same $\mathrm{P}$ fwd forward primer along with a new $\mathrm{P}$ rev2 reverse primer, spanning the entire floxed sequence, allowing the simultaneous detection of all three $\left(S y k^{+}, S y k^{\text {flox }}\right.$, and $\left.S y k^{\Delta}\right)$ alleles. We then cultured wild type, $S y k^{\Delta \mathrm{OC}}$ and $S y k^{\Delta \text { Haemo }}$ bone marrow cells in the presence of M-CSF and RANKL for different periods of time and analyzed their genomic DNA with both the PCR 1 (Figure 10B) and PCR 2 (Figure 10C) protocols.

Results with PCR 1 are shown in Figure 10B. In line with our expectations, the $S y k^{+}$allele was present throughout the assay period in wild type osteoclast cultures and the $S y k^{\text {flox }}$ allele was present in all $S y k^{\Delta \mathrm{OC}}$ samples. Though the latter finding indicated the presence of the non-recombined $S y k^{\text {flox }}$ allele throughout osteoclast development, it did not exclude 


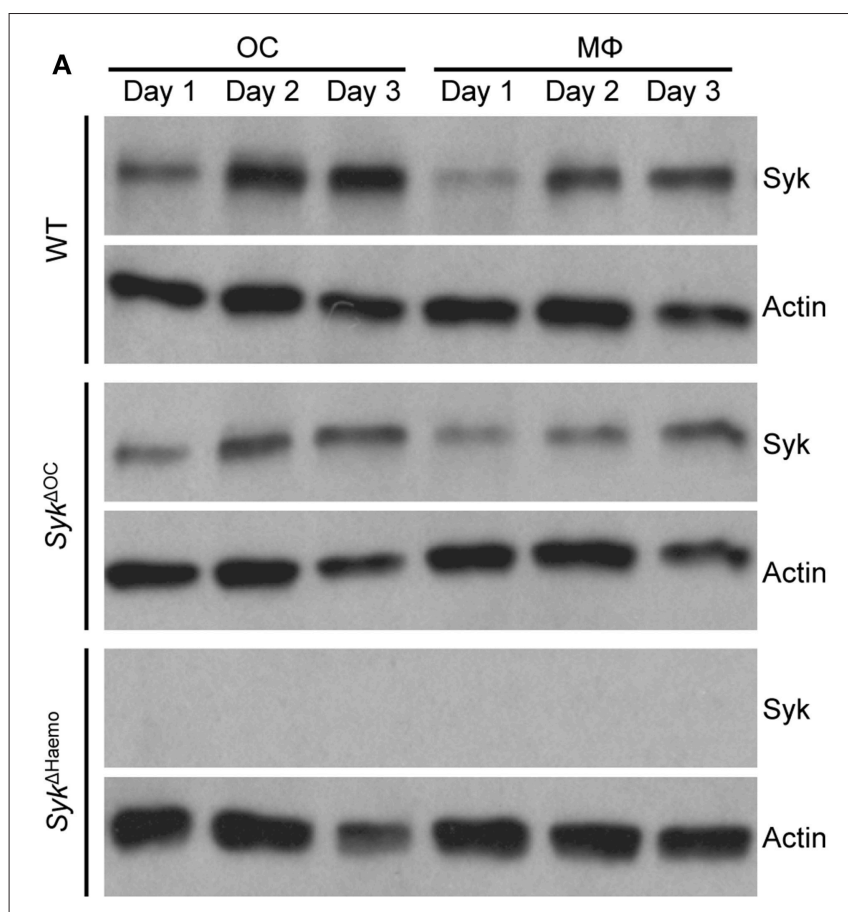

B

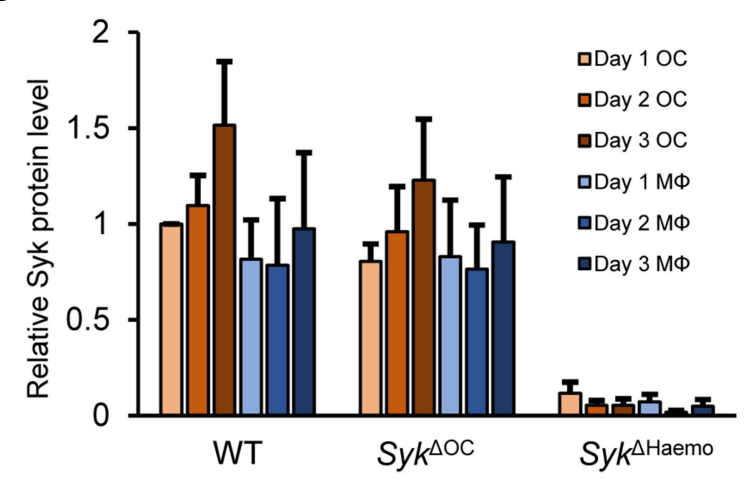

FIGURE 9 | Analysis of the level of Syk protein in osteoclast and macrophage cultures. Bone marrow-derived myeloid progenitors from wild type (WT), Syk ${ }^{\Delta \mathrm{OC}}$ or Syk ${ }^{\Delta \text { Haemo }}$ mice were cultured in the presence of $50 \mathrm{ng} / \mathrm{ml} \mathrm{M}$-CSF with (osteoclasts; OC) or without (macrophages; MФ) $50 \mathrm{ng} / \mathrm{ml}$ RANKL for the indicated times. Whole-cell lysates were then prepared and processed for immunoblotting for Syk, or for actin as a loading control. Representative immunoblots (A) or quantification of Syk/actin ratios normalized to Day 1 OC (B) are shown. Blots are representative of, and bar graphs show mean and SEM from, 3 to 6 independent experiments.

substantial deletion (reduction) of the $S y k^{\text {flox }}$ allele given the tendency of PCR to amplify even small amounts of the target templates when no competing templates are present. In contrast, neither the $S y k^{+}$nor the $S y k^{\text {flox }}$ allele could be amplified from $S y k^{\Delta \text { Haemo }}$ cultures (Figure 10B), suggesting complete deletion of the $S y k^{\text {flox }}$ allele from those cells, likely in an earlier stage of hematopoietic development. Unfortunately, the $S y k^{\Delta}$ allele could not be detected with the PCR 1 protocol (Figure 10B and Supplementary Figure 2).
Results with PCR 2 (which could detect all three alleles including the $S y k^{\Delta}$ allele; see Supplementary Figure 2) is shown in Figure 10C. Those experiments confirmed the expected exclusive presence of the $S y k^{+}$allele throughout the experiment in wild type cultures, as well as the exclusive presence of the $S y k^{\Delta}$ allele throughout the $S y k^{\Delta \text { Haemo }}$ samples, indicating complete deletion of the $S y k^{\text {flox }}$ allele in the $S y k^{\Delta \text { Haemo }}$ cultures. In contrast to the static picture in wild type and $S y k^{\Delta \text { Haemo }}$ cultures, the $S y k^{\triangle \mathrm{OC}}$ cultures showed dynamic changes in the Syk locus (Figure 10C). While only the $S y k^{\text {flox }}$ allele was seen 1 day after the initial RANKL treatment, the $S y k^{\Delta}$ allele appeared and its amount gradually increased during the next 3 days, parallel to a proportional decline (but not complete disappearance) of the $S y k^{\text {flox }}$ allele (Figure 10C). It should be noted that the appearance of the smaller-size $S y k^{\Delta}$ allele likely had a competitive advantage over the larger-size $S y k^{\text {flox }}$ allele in these PCR reactions, leading to a likely underestimation of the amount of the $S y k^{\text {flox }}$ allele. Taken together, those results and the time course of the changes indicate that Ctsk-Cre-mediated deletion of the $S y k^{\text {flox }}$ allele occurs gradually during 2-4 days after RANKL addition and that only an incomplete genetic deletion of Syk is achieved even until the end of the observation period.

The above results indicate slow and gradual deletion of the $S y k^{\text {flox }}$ allele in $S y k^{\Delta O C}$ osteoclast cultures, which is in line with the slow activation of the Ctsk gene during in vitro osteoclast development (Figures 8, 10A) $(54,55)$. These results may also explain the less severe in vivo phenotypes (Figures 1-5) and less pronounced in vitro osteoclast developmental defect (Figure 6), as well as the continuous presence of Syk in osteoclast cultures (Figure 9), in the $S y k^{\Delta \mathrm{OC}}$ mutants, as compared with the $S y k^{\Delta \text { Haemo }}$ mutants which show early and complete deletion of the $S y k^{\text {flox }}$ allele from the beginning of the entire osteoclast developmental process.

\section{Analysis of Myeloid-Specific Syk Deletion}

Osteoclasts are derived from early myeloid progenitors through a developmental process related to that of macrophages. Therefore, we have also tested certain aspects of osteoclast biology in $S y k^{\Delta \text { Myelo }}$ mutants in which Syk is conditionally deleted using the myeloid-specific LysM-Cre knock-in mutation. The $S y k^{\Delta \text { Myelo }}$ mutation strongly reduced (but did not completely abrogate) osteoclast development, both in terms of the number of osteoclasts (Supplementary Figure 3A) and the area covered by osteoclasts (Supplementary Figure 3B). As shown in Supplementary Figure 3C, Syk expression was strongly reduced (but did not completely disappear) in both $S y k^{\Delta \text { Myelo }}$ osteoclasts and macrophages. The $S y k^{\Delta \text { Myelo }}$ mutation also partially reduced osteoclast-specific gene expression, i.e., the upregulation of the mRNA of the Tm7sf4, Acp5, Calcr, Nfatc1, and Ctsk genes (Supplementary Figure 3D). We have also tested Cre

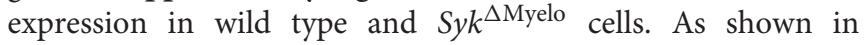
Supplementary Figure 3D, Cre mRNA was absent from wild type cells but it was expressed in all $S y k^{\Delta \text { Myelo }}$ samples. Interestingly, Cre expression was especially high in early myeloid progenitors (Day 0 samples) and declined afterwards both in osteoclast and macrophage cultures. Taken together, the $S y k^{\Delta \text { Myelo }}$ mutation leads to strong but incomplete deletion of 


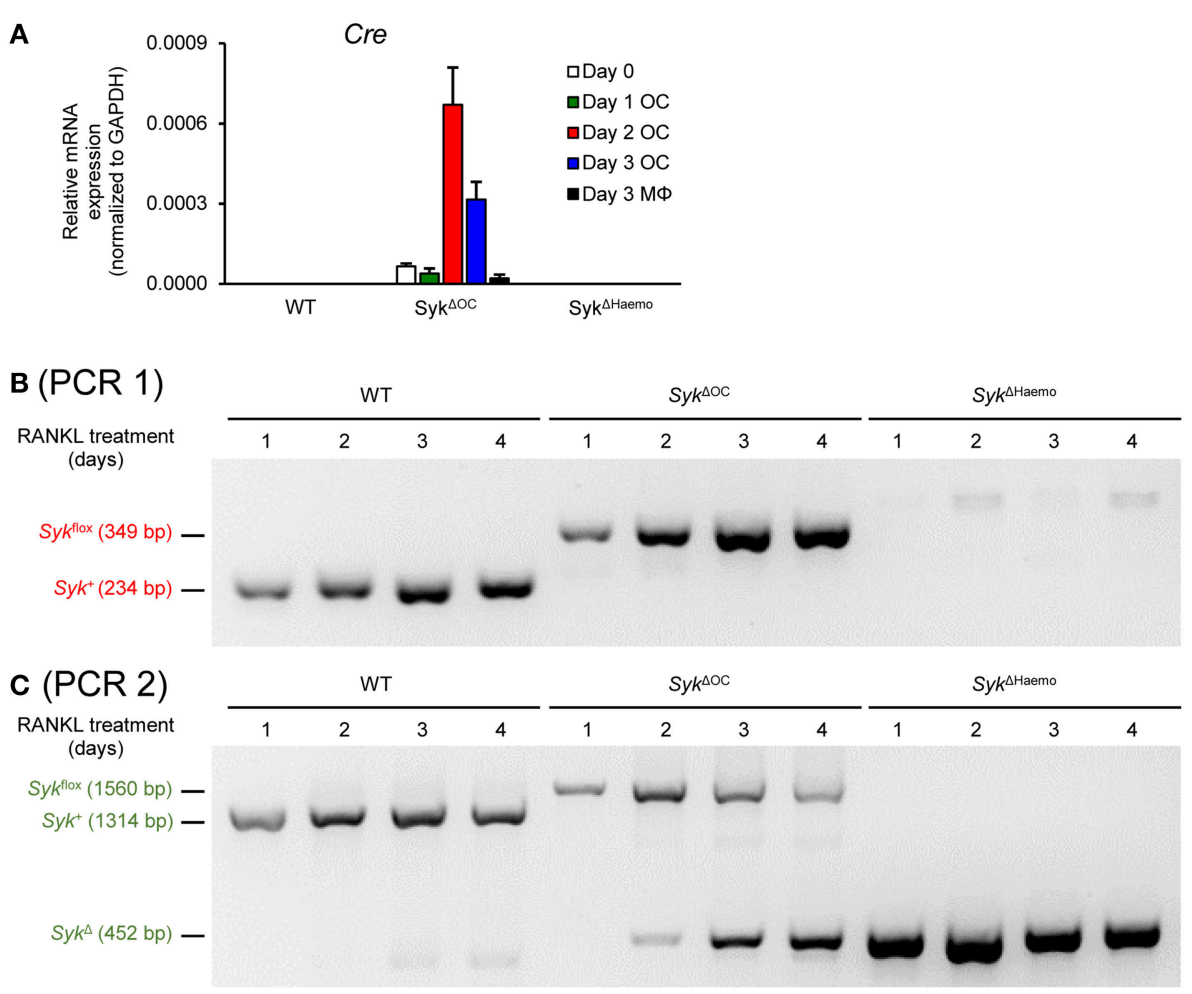

FIGURE 10 | Genetic analysis of Cre expression and Cre-mediated Syk deletion. (A) Cre expression in wild type (WT), Syk ${ }^{\Delta O C}$ or Syk ${ }^{\Delta H a e m o}$ mice bone marrow-derived cells cultured for 0-3 days in the presence of $50 \mathrm{ng} / \mathrm{ml} \mathrm{M}-\mathrm{CSF}$ with (osteoclasts; OC) or without (macrophages; M $\Phi$ ) $50 \mathrm{ng} / \mathrm{ml}$ RANKL. Bar graph shows mean and SEM from 3 independent experiments. (B,C) PCR analysis of wild type (WT), Syk ${ }^{\Delta O C}$ or Syk ${ }^{\Delta H_{1}}$ oemo osteoclast cultures (differentiated in the presence of $50 \mathrm{ng} / \mathrm{ml}$ RANKL and M-CSF for $1-4$ days) using PCR 1 (P fwd vs. P rev1 primers; B) or PCR 2 (P fwd vs. P rev2 primers; C). Images are representative of 4 independent experiments.

Syk during early myeloid differentiation, leading to strongly reduced but not completely abrogated in vitro development of osteoclasts.

\section{DISCUSSION}

In this manuscript, we provide direct genetic evidence for the role of the Syk tyrosine kinase in normal bone homeostasis in adult mice. The perinatal lethality of $S y k^{-/-}$mice was overcome by lineage-specific conditional deletion of Syk in osteoclasts $\left(S y k^{\triangle \mathrm{OC}}\right.$ mice) or in the entire hematopoietic system ( $S y k^{\Delta \text { Haemo }}$ mice). Both osteoclast-specific and hematopoietic Syk deletion led to increased trabecular bone mass and defective in vitro osteoclast development and function. However, hematopoietic Syk deletion caused more robust changes than osteoclast-specific Syk deletion both in vivo and in vitro. Our results suggest that this is due to late and incomplete deletion of Syk in osteoclastspecific Syk mutants, likely caused by late activation and modest activity of Cre expression driven by the Ctsk gene promoter during osteoclast development.

We and others have previously shown that Syk plays an important role in in vitro osteoclast development and osteoclastmediated resorptive activity $(40,42,44)$. However, the role of Syk in bone homeostasis in live mice could not be tested because of the perinatal lethality of $S y k^{-/-}$mice $(17,18)$, although bone density appeared to be increased in third-trimester $S y k^{-1-}$ fetuses (44). Unfortunately, the in vitro osteoclast phenotypes cannot be directly extrapolated to the in vivo situation since a number of mutations even within the same pathway, such as DAP12 $(38,41-43)$ or PLC $22(54,58,59)$ deficiency, provide examples of practically complete in vitro osteoclast defects despite only moderately increased in vivo bone mass. Our in vivo results, especially those with the $S y k^{\Delta \text { Haemo }}$ mice, provide the first direct genetic evidence for a major and critical role of Syk in bone homeostasis in live animals.

The two main models used in this study clarify different aspects of the role of Syk in bone metabolism: the $S y k^{\Delta \mathrm{OC}}$ mice provide evidence for an osteoclast-specific role of Syk but it only leads to limited defects, while the $S y k^{\Delta \text { Haemo }}$ mice have the widest Syk deletion without embryonic lethality and therefore show the maximum extent of bone resorption defects.

Despite the clear in vivo phenotypes of conditional Sykdeficient mice, a number of questions related to the cell type(s) responsible remain open. Our experiments with the $S y k^{\Delta \mathrm{OC}}$ mice indicate that the role of Syk in bone metabolism is at least in part mediated by Syk expression in osteoclasts. However, it is at present unclear why $S y k^{\Delta \text { Haemo }}$ mice have a more severe phenotype than the $S y k^{\Delta \mathrm{OC}}$ animals. A reasonable explanation, 
also supported by our in vitro findings, is that the $S y k^{\Delta \mathrm{OC}}$ mutation only partially deletes Syk in the osteoclast lineage (see further discussion below). However, we cannot exclude the possibility that changes to (a) hematopoietic lineage(s) other than osteoclasts in the $S y k^{\Delta \text { Haemo }}$ mice also contribute to the increased bone mass. In addition, it is also possible that Syk deletion in osteoclasts and/or other hematopoietic cells indirectly promote osteoblast-mediated bone production. It should be mentioned that prior studies (44) showed normal bone production by $S y k^{-1-}$ osteoblasts, therefore it is unlikely that Syk deficiency in osteoblasts (e.g., through a leaky Cre expression) contributes to the observed in vivo bone phenotypes. It should also be noted that our micro-CT studies indicate increased trabecular number rather than a higher trabecular thickness as the main cause of the in vivo bone phenotypes. Unfortunately, different groups have reported different contributions of the changes of trabecular number and trabecular thickness to increased bone mass linked to osteoclast defects $(42,43,54,55)$, making it rather difficult to determine the contribution of osteoclasts and osteoblasts to a bone phenotype based on micro-CT data.

An interesting question arising from this study is why the $S y k^{\Delta \mathrm{OC}}$ mutation causes a less severe osteoclast phenotype than the $S y k^{\Delta \text { Haemo }}$ mutation. Our results clearly indicate that the $S y k^{\triangle \mathrm{OC}}$ mutation is less effective in inactivating the Syk gene in osteoclasts. One possible explanation is the fact that the Ctsk-Cre mutation triggers Cre activation at a relatively later time point (starting at $\sim 2$ days after RANKL treatment) which, combined with the likely continued presence of the preexisting Syk mRNA and Syk protein beyond complete deletion of both Syk alleles, may lead to a late disappearance of the Syk protein at a time point where osteoclast development and osteoclast-mediated bone resorption has already occurred. The activation kinetics of the Ctsk gene (Figure 8) and of the Ctsk-Cre mutation (Figure 10A), as well as the late appearance of the $S y k^{\Delta}$ allele (Figure 10C) all support this explanation. Another possible explanation is that the level of Cre expression from the Ctsk-Cre mutation is too low to provide complete Syk deletion and therefore a significant amount of Syk remains present even after activation of the Ctsk-Cre mutation. In this respect, it is interesting to see that the maximum level of Cre expression in $S y k^{\Delta O C}$ cultures (Figure 10A) is at least an order of magnitude less than that in the $S y k^{\Delta \text { Myelo }}$ cultures (Supplementary Figure 3D). Nevertheless, both scenarios and our own results are consistent with prior reports from the literature showing good specificity but incomplete deletion of target genes (incomplete penetrance) by the Ctsk-Cre mutation $(54,55,60)$. Those results also point to the fact that the suitability of Cre-expressing mouse strains for the lineage-specific deletion of floxed alleles depends not only on the specificity of the Cre expression but also on its timing, i.e., whether sufficient time is available for nearly complete deletion of the target gene.

Though the main message of our manuscript is the increased in vivo bone mass upon conditional deletion of Syk in live mice, some of our results also address the mechanism of the contribution of Syk to osteoclast development and function. While osteoclast-specific gene expression was reduced in $S y k^{\Delta \mathrm{OC}}$ and $S y k^{\Delta \text { Myelo }}$ cultures, it was not completely abrogated even in $S y k^{\Delta \text { Myelo }}$ cells which practically completely lacked Syk protein expression. Therefore, Syk may not only be involved in osteoclast-specific gene expression but maybe also in later processes such as (pre)osteoclast fusion or the osteoclastmediated resorption process. It is particularly interesting in this respect that DC-STAMP was only moderately affected by Syk deletion, suggesting that a possible role of Syk in (pre)osteoclast fusion may rely on mechanisms other than DCSTAMP expression. It is also worth noting that practically complete defect of matrix resorption was seen in both $S y k^{\Delta O C}$ and $S y k^{\Delta \text { Myelo }}$ cultures (i.e., no substantial difference between the two mutations could be seen in this assay), which, however, is complicated by the fact that this assay measures both osteoclast development and the resorptive activity of the cells, and that the longer culture period could have allowed more complete Syk deletion by the Ctsk-Cre mutation. It is also of interest why the number of osteoclasts are reduced on Day 3.5 in the $S y k^{\Delta \mathrm{OC}}$ cultures (Figure 6). This may be simply due to the fusion of the cells reducing the number of individual osteoclasts, apoptotic disappearance of osteoclasts during this late stage of culture, and/or active deletion of Syk toward that time period.

We and others have shown that Syk is required for the development of autoantibody-induced arthritis in experimental mice $(24,33-35)$ and Syk has been proposed as a therapeutic target in human rheumatoid arthritis (61-63). A possible role for Syk in various immune and other cells such as neutrophils, macrophages, mast cells or even platelets $(16,22-$ 24, 26-29, 31, 64-67) may provide an explanation for this observation. Nevertheless, it is important to note that both murine arthritis models (33) and human rheumatoid arthritis (5) are accompanied with bone erosions. Therefore, the role of Syk in osteoclast-mediated in vivo bone resorption may also provide an additional cell type beyond immune/inflammatory cells in which Syk inhibitors may have a beneficial therapeutic effect. In addition, Syk-mediated bone resorption may also be a therapeutic target in other diseases characterized by osteoclastmediated bone resorption such as osteoporosis (4) or osteolytic cancer metastases $(7,8)$.

Taken together, our results provide direct genetic evidence for the role of Syk in in vivo bone metabolism and therefore may contribute to the rationale of developing Syk inhibitors for the treatment of diseases characterized by pathologic bone loss.

\section{ETHICS STATEMENT}

All animal experiments were approved by the Animal Experimentation Review Board of the Semmelweis University.

\section{AUTHOR CONTRIBUTIONS}

DC, DG, and AM conceived the study, designed the experiments, analyzed, and interpreted the data and wrote the manuscript. DC and ES performed most of the experiments. AA and SB performed the qPCR experiments. PA and ZJ performed the histological studies. CD-N conducted the micro-CT scanning. AM supervised the project. 


\section{FUNDING}

This work was supported by the Hungarian National Scientific Research Fund (NKFIH-OTKA Grant No. K119653 to AM), the Lendület program of the Hungarian Academy of Sciences (LP2014-4/2018 to ZJ), the Faculty of Medicine of the University of Debrecen (Bridging and Intramural Research Grants to SB) and the Higher Education Institutional Excellence Program of Hungary. SB was a recipient of a János Szodoray Postdoctoral Fellowship from the University of Debrecen. AA held a Stipendium Hungaricum Scholarship from the Government of Hungary.

\section{REFERENCES}

1. Boyle WJ, Simonet WS, Lacey DL. Osteoclast differentiation and activation. Nature. (2003) 423:337-42. doi: 10.1038/nature01658

2. Ono T, Nakashima T. Recent advances in osteoclast biology. Histochem Cell Biol. (2018) 149:325-41. doi: 10.1007/s00418-018-1636-2

3. Sobacchi C, Schulz A, Coxon FP, Villa A, Helfrich MH. Osteopetrosis: genetics, treatment and new insights into osteoclast function. Nat Rev Endocrinol. (2013) 9:522-36. doi: 10.1038/nrendo.2013.137

4. Rachner TD, Khosla S, Hofbauer LC. Osteoporosis: now and the future. Lancet. (2011) 377:1276-87. doi: 10.1016/S0140-6736(10)62349-5

5. Schett G, Gravallese E. Bone erosion in rheumatoid arthritis: mechanisms, diagnosis and treatment. Nat Rev Rheumatol. (2012) 8:656-64. doi: 10.1038/nrrheum.2012.153

6. Le Goff B, Berthelot JM, Maugars Y, Heymann D. Osteoclasts in RA: diverse origins and functions. Joint Bone Spine. (2013) 80:58691. doi: 10.1016/j.jbspin.2013.04.002

7. Clezardin P. Pathophysiology of bone metastases from solid malignancies. Joint Bone Spine. (2017) 84:677-84. doi: 10.1016/j.jbspin.2017.05.006

8. Sousa S, Clezardin P. Bone-Targeted Therapies in Cancer-Induced Bone Disease. Calcif Tissue Int. (2018) 102:227-50. doi: 10.1007/s00223-017-0353-5

9. Wada T, Nakashima T, Hiroshi N, Penninger JM. RANKL-RANK signaling in osteoclastogenesis and bone disease. Trends Mol Med. (2006) 12:1725. doi: 10.1016/j.molmed.2005.11.007

10. Yoshida H, Hayashi S, Kunisada T, Ogawa M, Nishikawa S, Okamura $\mathrm{H}$, et al. The murine mutation osteopetrosis is in the coding region of the macrophage colony stimulating factor gene. Nature. (1990) 345:4424. doi: $10.1038 / 345442 \mathrm{a} 0$

11. Dougall WC, Glaccum M, Charrier K, Rohrbach K, Brasel K, De Smedt T, et al. RANK is essential for osteoclast and lymph node development. Genes Dev. (1999) 13:2412-24. doi: 10.1101/gad.13.18.2412

12. Li J, Sarosi I, Yan XQ, Morony S, Capparelli C, Tan HL, et al. RANK is the intrinsic hematopoietic cell surface receptor that controls osteoclastogenesis and regulation of bone mass and calcium metabolism. Proc Natl Acad Sci USA. (2000) 97:1566-71. doi: 10.1073/pnas.97.4.1566

13. Kong YY, Yoshida H, Sarosi I, Tan HL, Timms E, Capparelli C, et al. OPGL is a key regulator of osteoclastogenesis, lymphocyte development and lymph-node organogenesis. Nature. (1999) 397:315-23. doi: 10.1038/16852

14. Kim N, Odgren PR, Kim DK, Marks SC, Jr., Choi Y. Diverse roles of the tumor necrosis factor family member TRANCE in skeletal physiology revealed by TRANCE deficiency and partial rescue by a lymphocyteexpressed TRANCE transgene. Proc Natl Acad Sci USA. (2000) 97:1090510. doi: 10.1073/pnas.200294797

15. McHugh KP, Hodivala-Dilke K, Zheng MH, Namba N, Lam J, Novack $\mathrm{D}$, et al. Mice lacking $\beta 3$ integrins are osteosclerotic because of dysfunctional osteoclasts. J Clin Invest. (2000) 105:433-40. doi: 10.1172/JC I8905

16. Mócsai A, Ruland J, Tybulewicz VL. The SYK tyrosine kinase: a crucial player in diverse biological functions. Nat Rev Immunol. (2010) 10:38702. doi: $10.1038 /$ nri2765

17. Turner M, Mee PJ, Costello PS, Williams O, Price AA, Duddy LP, et al. Perinatal lethality and blocked B-cell development in mice lacking

\section{ACKNOWLEDGMENTS}

We thank Nóra Kiss for expert technical assistance, Bence T. Szabó for help with micro-CT scanning, and Shigeaki Kato and Alexander Tarakhovsky for sharing mutant mouse strains.

\section{SUPPLEMENTARY MATERIAL}

The Supplementary Material for this article can be found online at: https://www.frontiersin.org/articles/10.3389/fimmu. 2019.00937/full\#supplementary-material

the tyrosine kinase Syk. Nature. (1995) 378:298-02. doi: 10.1038/378 $298 \mathrm{a} 0$

18. Cheng AM, Rowley B, Pao W, Hayday A, Bolen JB, Pawson T. Syk tyrosine kinase required for mouse viability and B-cell development. Nature. (1995) 378:303-6. doi: 10.1038/378303a0

19. Kiefer F, Brumell J, Al-Alawi N, Latour S, Cheng A, Veillette A, et al. The Syk protein tyrosine kinase is essential for $\mathrm{Fc} \gamma$ receptor signaling in macrophages and neutrophils. Mol Cell Biol. (1998) 18:420920. doi: 10.1128/MCB.18.7.4209

20. Costello PS, Turner M, Walters AE, Cunningham CN, Bauer PH, Downward J, et al. Critical role for the tyrosine kinase Syk in signalling through the high affinity IgE receptor of mast cells. Oncogene. (1996) 13:2595-605.

21. Crowley MT, Costello PS, Fitzer-Attas CJ, Turner M, Meng F, Lowell $\mathrm{C}$, et al. A critical role for Syk in signal transduction and phagocytosis mediated by Fc $\gamma$ receptors on macrophages. J Exp Med. (1997) 186:102739. doi: 10.1084/jem.186.7.1027

22. Mócsai A, Zhang H, Jakus Z, Kitaura J, Kawakami T, Lowell CA. G-proteincoupled receptor signaling in Syk-deficient neutrophils and mast cells. Blood. (2003) 101:4155-63. doi: 10.1182/blood-2002-07-2346

23. Meinders M, Hoogenboezem M, Scheenstra MR, De Cuyper IM, Papadopoulos P, Németh $T$, et al. Repercussion of megakaryocyte-specific Gatal loss on megakaryopoiesis and the hematopoietic precursor compartment. PLoS ONE. (2016) 11:e0154342. doi: 10.1371/journal.pone.0154342

24. Németh T, Futosi K, Szilveszter K, Vilinovszki O, Kiss-Pápai L, Mócsai A. Lineage-specific analysis of Syk function in autoantibody-induced arthritis. Front Immunol. (2018) 9:555. doi: 10.3389/fimmu.2018.00555

25. Vines CM, Potter JW, Xu Y, Geahlen RL, Costello PS, Tybulewicz $\mathrm{VL}$, et al. Inhibition of $\mathrm{b} 2$ integrin receptor and Syk kinase signaling in monocytes by the Src family kinase Fgr. Immunity. (2001) 15:50719. doi: 10.1016/S1074-7613(01)00221-7

26. Mócsai A, Zhou M, Meng F, Tybulewicz VL, Lowell CA. Syk is required for integrin signaling in neutrophils. Immunity. (2002) 16:54758. doi: 10.1016/S1074-7613(02)00303-5

27. Obergfell A, Eto K, Mócsai A, Buensuceso C, Moores SL, Brugge JS, et al. Coordinate interactions of Csk, Src, and Syk kinases with $\alpha \operatorname{IIb} \beta 3$ initiate integrin signaling to the cytoskeleton. J Cell Biol. (2002) 157:26575. doi: $10.1083 / \mathrm{jcb} .200112113$

28. Abtahian F, Guerriero A, Sebzda E, Lu MM, Zhou R, Mócsai A, et al. Regulation of blood and lymphatic vascular separation by signaling proteins SLP-76 and Syk. Science. (2003) 299:247-51. doi: 10.1126/science.1079477

29. Mócsai A, Abram CL, Jakus Z, Hu Y, Lanier LL, Lowell CA. Integrin signaling in neutrophils and macrophages uses adaptors containing immunoreceptor tyrosine-based activation motifs. Nat Immunol. (2006) 7:1326-33. doi: 10.1038/ni1407

30. Abtahian F, Bezman N, Clemens R, Sebzda E, Cheng L, Shattil SJ, et al. Evidence for the requirement of ITAM domains but not SLP-76/Gads interaction for integrin signaling in hematopoietic cells. Mol Cell Biol. (2006) 26:6936-49. doi: 10.1128/MCB.01040-06

31. Fodor S, Jakus Z, Mócsai A. ITAM-based signaling beyond the adaptive immune response. Immunol Lett. (2006) 104:2937. doi: 10.1016/j.imlet.2005.11.001 
32. Jakus Z, Fodor S, Abram CL, Lowell CA, Mócsai A. Immunoreceptorlike signaling by $\beta 2$ and $\beta 3$ integrins. Trends Cell Biol. (2007) 17:493501. doi: 10.1016/j.tcb.2007.09.001

33. Jakus Z, Simon E, Balázs B, Mócsai A. Genetic deficiency of Syk protects mice from autoantibody-induced arthritis. Arthritis Rheum. (2010) 62:1899910. doi: 10.1002/art.27438

34. Elliott ER, Van Ziffle JA, Scapini P, Sullivan BM, Locksley RM, Lowell CA. Deletion of Syk in neutrophils prevents immune complex arthritis. J Immunol. (2011) 187:4319-30. doi: 10.4049/jimmunol.1100341

35. Ozaki N, Suzuki S, Ishida M, Harada Y, Tanaka K, Sato Y, et al. Syk-dependent signaling pathways in neutrophils and macrophages are indispensable in the pathogenesis of anti-collagen antibody-induced arthritis. Int Immunol. (2012) 24:539-50. doi: 10.1093/intimm/dxs078

36. Németh T, Virtic O, Sitaru C, Mócsai A. The Syk tyrosine kinase is required for skin inflammation in an in vivo mouse model of epidermolysis bullosa acquisita. J Invest Dermatol. (2017) 137:2131-9. doi: 10.1016/j.jid.2017.05.017

37. Samavedam UK, Mitschker N, Kasprick A, Bieber K, Schmidt E, Laskay $\mathrm{T}$, et al. Whole-genome expression profiling in skin reveals SYK as a key regulator of inflammation in experimental epidermolysis bullosa acquisita. Front Immunol. (2018) 9:249. doi: 10.3389/fimmu.2018.00249

38. Kaifu T, Nakahara J, Inui M, Mishima K, Momiyama T, Kaji M, et al. Osteopetrosis and thalamic hypomyelinosis with synaptic degeneration in DAP12-deficient mice. J Clin Invest. (2003) 111:323-32. doi: 10.1172/JCI16923

39. Paloneva J, Mandelin J, Kiialainen A, Bohling T, Prudlo J, Hakola $\mathrm{P}$, et al. DAP12/TREM2 deficiency results in impaired osteoclast differentiation and osteoporotic features. J Exp Med. (2003) 198:669-75. doi: 10.1084/jem.20030027

40. Faccio R, Zou W, Colaianni G, Teitelbaum SL, Ross FP. High dose M-CSF partially rescues the Dap12-/- osteoclast phenotype. J Cell Biochem. (2003) 90:871-83. doi: 10.1002/jcb.10694

41. Humphrey MB, Ogasawara K, Yao W, Spusta SC, Daws MR, Lane NE, et al. The signaling adapter protein DAP12 regulates multinucleation during osteoclast development. J Bone Miner Res. (2004) 19:224-34. doi: 10.1359/JBMR.0301234

42. Mócsai A, Humphrey MB, Van Ziffle JA, Hu Y, Burghardt A, Spusta SC, et al. The immunomodulatory adapter proteins DAP12 and Fc receptor $\gamma$-chain $(\mathrm{FcR} \gamma)$ regulate development of functional osteoclasts through the Syk tyrosine kinase. Proc Natl Acad Sci USA. (2004) 101:615863. doi: 10.1073/pnas.0401602101

43. Koga $\mathrm{T}$, Inui $\mathrm{M}$, Inoue $\mathrm{K}$, Kim $\mathrm{S}$, Suematsu $\mathrm{A}$, Kobayashi $\mathrm{E}$, et al. Costimulatory signals mediated by the ITAM motif cooperate with RANKL for bone homeostasis. Nature. (2004) 428:758-63. doi: 10.1038/nature02444

44. Zou W, Kitaura H, Reeve J, Long F, Tybulewicz VL, Shattil SJ, et al. Syk, c-Src, the $\alpha \mathrm{V} \beta 3$ integrin, and ITAM immunoreceptors, in concert, regulate osteoclastic bone resorption. J Cell Biol. (2007) 176:87788. doi: $10.1083 /$ jcb. 200611083

45. Zou W, Croke M, Fukunaga T, Broekelmann TJ, Mecham RP, Teitelbaum SL. Zap70 inhibits Syk-mediated osteoclast function. J Cell Biochem. (2013) 114:1871-8. doi: 10.1002/jcb.24531

46. Takayanagi H. Osteoimmunology: shared mechanisms and crosstalk between the immune and bone systems. Nat Rev Immunol. (2007) 7:292304. doi: $10.1038 /$ nri2062

47. Okamoto K, Nakashima T, Shinohara M, Negishi-Koga T, Komatsu $\mathrm{N}$, Terashima A, et al. Osteoimmunology: the conceptual framework unifying the immune and skeletal systems. Physiol Rev. (2017) 97:1295349. doi: 10.1152/physrev.00036.2016

48. Zou W, Reeve JL, Liu Y, Teitelbaum SL, Ross FP. DAP12 Couples c-Fms Activation to the Osteoclast Cytoskeleton by Recruitment of Syk. Mol Cell. (2008) 31:422-31. doi: 10.1016/j.molcel.2008.06.023

49. Saijo K, Schmedt C, Su IH, Karasuyama H, Lowell CA, Reth M, et al. Essential role of Src-family protein tyrosine kinases in NF- $\kappa \mathrm{B}$ activation during B cell development. Nat Immunol. (2003) 4:274-9. doi: 10.1038/ni893

50. Nakamura T, Imai Y, Matsumoto T, Sato S, Takeuchi K, Igarashi K, et al. Estrogen prevents bone loss via estrogen receptor $\alpha$ and induction of Fas ligand in osteoclasts. Cell. (2007) 130:811-23. doi: 10.1016/j.cell.2007.07.025

51. de Boer J, Williams A, Skavdis G, Harker N, Coles M, Tolaini M, et al. Transgenic mice with hematopoietic and lymphoid specific expression of Cre. Eur J Immunol. (2003) 33:314-25. doi: 10.1002/immu.200310005
52. Goodwin LO, Splinter E, Davis TL, Urban R, He H, Braun RE, et al. Large-scale discovery of mouse transgenic integration sites reveals frequent structural variation and insertional mutagenesis. bioRxiv. (2017) 236307. doi: 10.1101/236307

53. Clausen BE, Burkhardt C, Reith W, Renkawitz R, Forster I. Conditional gene targeting in macrophages and granulocytes using LysMcre mice. Transgenic Res. (1999) 8:265-77. doi: 10.1023/A:1008942828960

54. Kertész Z, Gyori D, Körmendi S, Fekete T, Kis-Tóth K, Jakus Z, et al. Phospholipase $\mathrm{C} \gamma 2$ is required for basal but not oestrogen deficiency-induced bone resorption. Eur J Clin Invest. (2012) 42:4960. doi: 10.1111/j.1365-2362.2011.02556.x

55. Gyori D, Csete D, Benko S, Kulkarni S, Mandl P, Dobó-Nagy C, et al. The phosphoinositide 3-kinase isoform PI3K $\beta$ regulates osteoclast-mediated bone resorption in humans and mice. Arthritis Rheumatol. (2014) 66:221021. doi: 10.1002 /art.38660

56. Benko S, Magalhaes JG, Philpott DJ, Girardin SE. NLRC5 limits the activation of inflammatory pathways. J Immunol. (2010) 185:1681-91. doi: 10.4049/jimmunol.0903900

57. Wu Y, Torchia J, Yao W, Lane NE, Lanier LL, Nakamura MC, et al. Bone microenvironment specific roles of ITAM adapter signaling during bone remodeling induced by acute estrogen-deficiency. PLOS ONE. (2007) 2:e586. doi: 10.1371/journal.pone.0000586

58. Mao D, Epple H, Uthgenannt B, Novack DV, Faccio R. PLC $\gamma 2$ regulates osteoclastogenesis via its interaction with ITAM proteins and GAB2. J Clin Invest. (2006) 116:2869-79. doi: 10.1172/JCI28775

59. Chen Y, Wang X, Di L, Fu G, Bai L, Liu J, et al. Phospholipase C $\gamma 2$ mediates RANKL-stimulated lymph node organogenesis and osteoclastogenesis. J Biol Chem. (2008) 283:29593-601. doi: 10.1074/jbc.M802493200

60. Okamoto M, Murai J, Imai Y, Ikegami D, Kamiya N, Kato S, et al. Conditional deletion of Bmprla in differentiated osteoclasts increases osteoblastic bone formation, increasing volume of remodeling bone in mice. J Bone Miner Res. (2011) 26:2511-22. doi: 10.1002/jbmr.477

61. Weinblatt ME, Kavanaugh A, Burgos-Vargas R, Dikranian AH, MedranoRamirez G, Morales-Torres JL, et al. Treatment of rheumatoid arthritis with a Syk kinase inhibitor: a twelve-week, randomized, placebo-controlled trial. Arthritis Rheum. (2008) 58:3309-18. doi: 10.1002/art.23992

62. Weinblatt ME, Kavanaugh A, Genovese MC, Musser TK, Grossbard EB, Magilavy DB. An oral spleen tyrosine kinase (Syk) inhibitor for rheumatoid arthritis. N Engl J Med. (2010) 363:1303-12. doi: 10.1056/NEJMoa1000500

63. Deng GM, Kyttaris VC, Tsokos GC. Targeting Syk in Autoimmune Rheumatic Diseases. Front Immunol. (2016) 7:78. doi: 10.3389/fimmu.2016.00078

64. Werninghaus K, Babiak A, Gross O, Holscher C, Dietrich H, Agger EM, et al. Adjuvanticity of a synthetic cord factor analogue for subunit Mycobacterium tuberculosis vaccination requires FcR $\gamma$-Syk-Card9-dependent innate immune activation. J Exp Med. (2009) 206:89-97. doi: 10.1084/jem.200 81445

65. Kitaura J, Song J, Tsai M, Asai K, Maeda-Yamamoto M, Mócsai A, et al. Evidence that IgE molecules mediate a spectrum of effects on mast cell survival and activation via aggregation of the FceRI. Proc Natl Acad Sci USA. (2003) 100:12911-6. doi: 10.1073/pnas. 1735525100

66. Frommhold D, Mannigel I, Schymeinsky J, Mócsai A, Poeschl J, Walzog B, et al. Spleen tyrosine kinase Syk is critical for sustained leukocyte adhesion during inflammation in vivo. BMC Immunol. (2007) 8:31. doi: 10.1186/1471-2172-8-31

67. Berton G, Mócsai A, Lowell CA. Src and Syk kinases: key regulators of phagocytic cell activation. Trends Immunol. (2005) 26:208-14. doi: 10.1016/j.it.2005.02.002

Conflict of Interest Statement: The authors declare that the research was conducted in the absence of any commercial or financial relationships that could be construed as a potential conflict of interest.

Copyright (C) 2019 Csete, Simon, Alatshan, Aradi, Dobó-Nagy, Jakus, Benkő, Győri and Mócsai. This is an open-access article distributed under the terms of the Creative Commons Attribution License (CC BY). The use, distribution or reproduction in other forums is permitted, provided the original author(s) and the copyright owner(s) are credited and that the original publication in this journal is cited, in accordance with accepted academic practice. No use, distribution or reproduction is permitted which does not comply with these terms. 